\title{
UTILIZAÇÃO DE FUNGOS ENTOMOPATOGÊNICOS PARA O CONTROLE DE Orthezia praelonga (STERNORRYNCHA:ORTHEZIIDAE)
}

\author{
Marcelo de Oliveira Garcia
}

\author{
Dissertação apresentada à Escola Superior de \\ Agricultura "Luiz de Queiroz", Universidade de São \\ Paulo, para obtenção do título de Mestre em Ciências, \\ Área de Concentração: Entomologia.
}

P I R A C I C A B A

Estado de São Paulo - Brasil

Abril - 2004 


\title{
UTILIZAÇÃO DE FUNGOS ENTOMOPATOGÊNICOS PARA O CONTROLE de Orthezia praelonga (STERNORRYNCHA:ORTHEZIIDAE)
}

\author{
Marcelo de Oliveira Garcia
}

Engenheiro Agrônomo

Orientador: Prof. Dr. SÉRGIO BATISTA ALVES

Dissertação apresentada à Escola Superior de

Agricultura "Luiz de Queiroz", Universidade de São

Paulo, para obtenção do título de Mestre em Ciências, Área de Concentração: Entomologia.

\author{
P I R A C I C A B A \\ Estado de São Paulo - Brasil
}

Abril 2004 


\section{Dados Internacionais de Catalogação na Publicação (CIP) DIVISÃO DE BIBLIOTECA E DOCUMENTAÇÃO - ESALQ/USP}

\section{Garcia, Marcelo de Oliveira}

Utilização de fungos entomopatogênicos para o controle de Orthezia praelonga

(Sternorryncha : Ortheziidae) / Marcelo de Oliveira Garcia. - - Piracicaba, 2004.

57 p. : il.

Dissertação (mestrado) - - Escola Superior de Agricultura Luiz de Queiroz, 2004.

Bibliografia.

1. Cochonilhas 2. Citricultura 3. Controle biológico 4. Fungos entomopatogênicos 5. Inseticidas biológicos I. Título

CDD 632.752

"Permitida a cópia total ou parcial deste documento, desde que citada a fonte - O autor" 


\section{AOS MEUS PAIS JAIME E ONÉLIA (IN MEMORIAN)}

Aos meus irmãos André, Denise, Rogério, Ricardo, Gabriela e Pedro

A Eliane

A Michele.

DEDICO E OFEREÇO 


\section{AGRADECIMENTOS}

Ao Prof. Dr. Sérgio Batista Alves pela amizade, confiança, orientação e pela oportunidade dada para realização deste trabalho.

À amiga e bióloga Solange Aparecida Vieira pelo auxílio na realização deste trabalho

Aos companheiros do Laboratório de Patologia e Controle Microbiano de Insetos: Ricardo, Rogério (Phyto), Giuliano (Kutuk), Luiz Padulla, Tamai, Marcel, Marcos Medeiros, Leonardo, Daniella Macedo, Luciana, Melissa, Michelle, Daniela, Adriana e Denis Sinisgalli (in memorian) pela amizade e colaboração no desenvolvimento deste trabalho.

À Eng. Agr. Heloisa Sabino Prates (CDA/SAA-Campinas) pelo incentivo e fornecimento de materiais usados neste trabalho.

À Daniella Macedo pelo auxílio nas análises estatísticas.

Ao amigo Nader Habib pela confecção do Summary.

Às bibliotecárias pela revisão e normatização desta dissertação.

A todos aqueles que contribuíram de alguma forma para realização deste projeto. 


\section{SUMÁRIO}

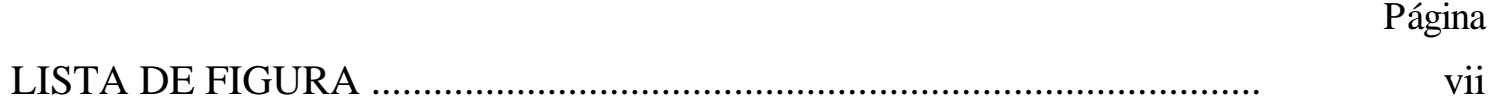

LISTA DE TABELAS ................................................................. viii

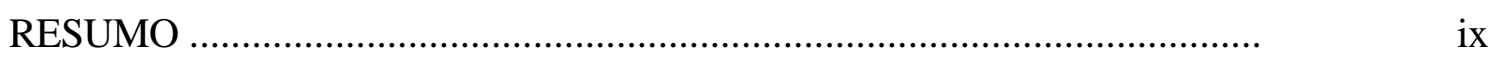

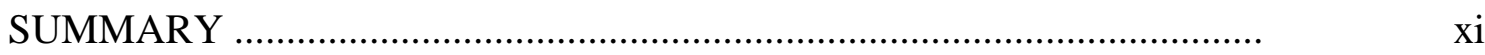

1 INTRODUÇÃ

2 REVISÃO DE LITERATURA ….................................................... 3

2.1 Importância e danos de Orthezia praelonga em citros ........................... 3

2.2 Orthezia praelonga ...........................................................................

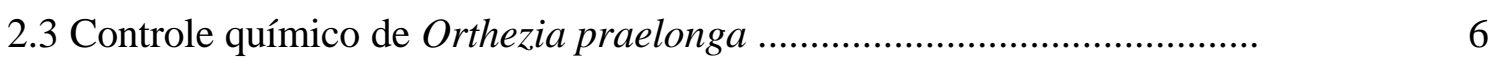

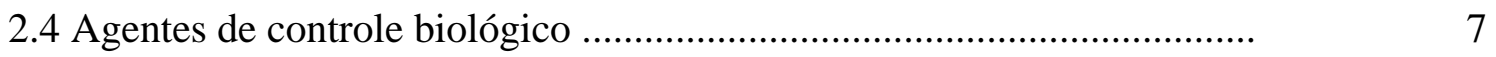

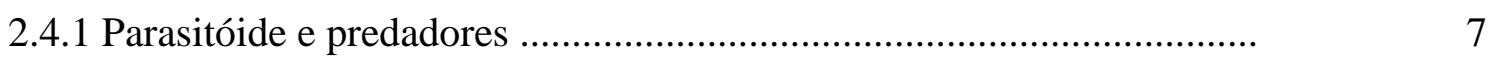

2.4.2 Fungos entomopatogênicos .......................................................

2.5 Seleção de isolados em programas de controle microbiano .....................

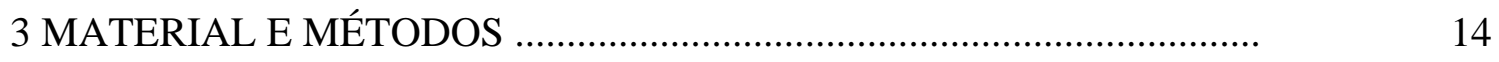

3.1 Criação e manutenção de Orthezia praelonga em laboratório ................. 14

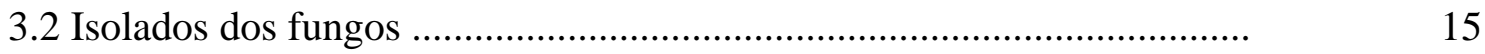

3.3 Bioensaios de seleção .................................................................. 18

3.4 Produção de conídios dos isolados em arroz pré-cozido pelo método de

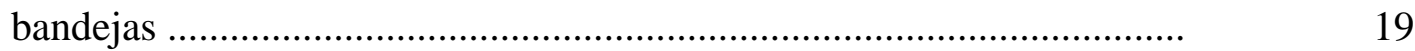

3.5 Produção de conídios dos isolados selecionados usando sistema de caixa com umidade forçada ............................................................. 20 
4 RESULTADOS E DISCUSSÕES .................................................. 23

4.1 Criação e manutenção de Orthezia praelonga em casa de vegetação..... 23

4.2 Seleção de isolados mais virulentos .................................................... 24

4.3 Produção do isolado selecionado em diferentes sistemas de produção.. 32

5. CONCLUSÕES ......................................................................

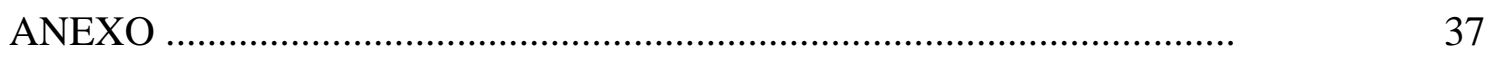

REFERÊNCIAS BIBLIOGRÁFICAS................................................. 


\section{LISTA DE FIGURAS}

Página

1 Folhas e frutos de citros infestados por Orthezia praeloga com fumagina

2 Procedência e hospedeiro dos fungos entomopatogênicos utilizados nos bioensaios com Orthezia praelonga

3 Produção fungos entomopatogênicos pelo método de bandejas

4 Caixa de produção de fungos entomopatogênicos. A- Vazia com sistema de aeração e água. B- Com anteparo metálico e tela para suporte do substrato C- Com substrato inoculado

5 Mortalidade corrigida de adultos de Orthezia praelonga após inoculação com isolados de fungos entomopatogênicos 


\section{LISTA DE TABELAS}

Página

1 Procedência e hospedeiro dos fungos entomopatogênicos utilizados nos

bioensaios com Orthezia praelonga ................................................... 


\title{
UTILIZAÇÃO DE FUNGOS ENTOMOPATOGÊNICOS PARA O CONTROLE DE ORTHEZIA PRAELONGA (STERNORRYNCHA:ORTHEZIIDAE)
}

\author{
Autor: MARCELO DE OLIVEIRA GARCIA \\ Orientador: Prof. Dr. SÉRGIO BATISTA ALVES
}

\section{RESUMO}

Avaliou-se a patogenicidade de 50 isolados de 8 espécies de fungos entomopatogênicos e o produto comercial Boveril ${ }^{\circledR}$, formulado com isolado ESALQ-447 de $B$. bassiana para ninfas de 2 e 3 ínstar de Orthezia praelonga. Em outro experimento avalio-se a produção do isolado selecionado em dois sistemas de produção. Nos ensaios de seleção foram usados tubetes de citros infestados pela cochonilha. O patógeno foi inoculado pulverizando-se $5 \mathrm{~mL}$ de suspensão conidial por muda, na concentração de $1 \mathrm{x}$ $10^{8}$ conídios $/ \mathrm{mL}$, utilizando-se um pulverizador com pressão constante de 0,5 libras/segundo. As mudas foram mantidas em estufas B.O.D. $\left(25 \pm 0,5^{\circ} \mathrm{C}, 70 \pm 10 \% \mathrm{UR}\right.$ e 12 horas de fotofase). Dos isolados testados, 30 foram patogênicos para cochonilha causando mortalidade corrigida que variaram de $1,0 \%$ a 46,6\%, sendo que os melhores resultados foram obtidos com os isolados ESALQ-972 e ESALQ-1300 de V. lecanii que proporcionaram 46,6 \% e 40,5\%, respectivamente, após 12 dias da aplicação. Para os testes de produção foram utilizados dois métodos. O método da bandeja no qual se utilizou o arroz pré-cozido, esterilizado e inoculado com fungo em bandejas de plástico, com ciclo de produção de 15 dias. No outro método, utilizou-se de uma caixa plástica, contendo uma lâmina d'água no fundo do recipiente e um sistema de aeração constante 
para fornecer pressão positiva e manter o ambiente com umidade acima de $90 \%$. O isolado testado foi o ESALQ-972, e os métodos da bandeja e da caixa proporcionaram produção de $1,8 \times 10^{9}$ e $1,0 \times 10^{9}$ conídios/grama de arroz, respectivamente. 


\title{
UTILIZATION OF ENTOMOPATHOGENIC FUNGI FOR THE CONTROL OF Orthezia praelonga (STERNORRYNCHA:ORTHEZIIDAE)
}

\author{
Author: MARCELO DE OLIVEIRA GARCIA \\ Adviser: Prof. Dr. SÉRGIO BATISTA ALVES
}

\section{SUMMARY}

The pathogenicity was evaluated for 50 isolates of 8 species of entomopathogenic fungi and the commercial product Boveril ${ }^{\circledR}$, composed by the isolate ESALQ-447 of B. bassiana for nymphs of 2 and 3 instar of Orthezia praelonga. In another experiment the production of the isolated was selected in two production systems. In the selection tests, seedlings of citrus infested by the scale were used. The pathogen was inoculated pulverizing $5 \mathrm{ml}$ of conidial suspension by seedlings, with a concentration of $1 \times 10^{8}$ conidia/ml, using a pulverizer with constant pressure of 0.5 $\mathrm{lbs} /$ second. The seedlings were kept in B.O.D. $\left(25 \pm 0,5^{\circ} \mathrm{C}, 70 \pm 10 \%\right.$ UR and 12 hours of photophase). From the isolates tested, 30 were pathogenic to the scale causing corrected mortality that varied from $1.0 \%$ to $46.6 \%$, while the best results were obtained with the isolates ESALQ-972 and ESALQ-1300 of V. lecanii which generated 46.6\% e 40.5\%, respectively, after 12 days of aplication. For the production tests two methods were utilized. The tray method, which used the pre-cocked rice, sterilized and inoculated with fungus in plastic trays, with a production cicle of 15 days. In the other method, a plastic box was used, containing a water blade in the bottom and a constant ventilation system to provide positive pressure and keep the environment with humidity above $90 \%$. The 
isolate tested was the ESALQ-972, resulting that the tray and the plastic box methods produced $1.88 \times 10^{9}$ and $1.0 \times 10^{9}$ conidia/gram of rice, respectively. 


\section{INTRODUÇÃO}

A citricultura é uma das mais importantes atividades agrícolas no Brasil, sendo a sua produção voltada especialmente para a exportação de suco concentrado, gerando divisas que ultrapassam US\$ 1 bilhão/ano (Neves et al., 2003). Pelo fato da cultura ser permanente e as áreas de plantio geralmente grandes, ocorre um elevado número de pragas e doenças. Pelo menos 50 espécies de artrópodos pragas entre ácaros, cochonilhas, percevejos, psilídeos, pulgões, moscas-brancas, besouros, lagartas e moscadas-frutas são de ocorrência comum em citros (Chiavegato, 1991; Nakano, 1991). Destas espécies, Gravena (1991) classificou como de maior importância o ácaro-daleprose e da falsa-ferrugem, mosca-das-frutas, bicho-furão e cochonilhas. No Brasil Orthezia praelonga é considerada como sendo a principal cochonilha que ocorre em Citrus spp. (Parra et al., 2003).

São conhecidas muitas espécies de cochonilhas atacando plantas cítricas nas diferentes regiões produtoras em todo mundo. Estas são divididas em dois grupos: as providas de carapaça e as desprovidas das mesmas. Estes insetos podem ser observados em todas as partes da planta como frutos, folhas, caules, ramos e raízes. Além da sucção da seiva, injetam toxinas e excretam substâncias açucaradas onde se desenvolve um fungo do gênero Capnodium, causador da 'fumagina", que cobre a folha e reduz área fotossintética da mesma.

As cochonilhas possuem importantes inimigos naturais no agroecossistema citrícola representados por artrópodos predadores e parasitóides, além de patógenos, especialmente fungos, que são responsáveis pelo controle de uma significativa porção de indivíduos que formam suas populações. 
Estudos visando a utilização e/ou preservação destes inimigos naturais, especialmente dos patógenos, nos diferentes agroecossistemas são ainda incipientes no Brasil, entretanto em alguns segmentos da agricultura, principalmente na citricultura onde os produtores encontram-se em um estágio mais avançado de organização, este problema vem sendo tratado com grande atenção já há algum tempo.

A cochonilha $O$. praelonga vem assumindo grande importância como praga nos últimos anos. Diversos citricultores têm procurado no setor de Entomologia da ESALQ/USP solução para o controle desta praga. Desta forma, o presente trabalho teve como objetivo selecionar e produzir isolados de fungos patogênicos para $O$. praelonga, visando sua utilização como inseticida microbiano. 


\section{REVISÃO DE LITERATURA}

\subsection{Importância e danos de Orthezia praelonga em citros}

As cochonilhas pertencem à ordem Hemiptera, subordem Sternorrhyncha. Segundo Gallo et al. (2002), existem cochonilhas que apresentam o corpo nu e outras possuem o corpo recoberto com cera. A cera é elaborada por glândulas epidérmicas, de forma variável, produzindo secreções pulverulentas que assumem aspecto de placas. Dentre as que são recobertas com cera, está a cochonilha O. praelonga, espécie de ocorrência freqüente em pomares citrícolas paulistas e que está amplamente distribuída em, praticamente, toda a América do Sul, onde é referida como infestante de plantas cultivadas, ornamentais e silvestres (Anexo A) (Rosamiglia, 1998).

Em 1942 Costa Lima já alertava que O. praelonga poderia se tornar uma praga de importância agrícola. Desde 1954 este inseto é considerado praga de importância econômica para a citricultura do Estado do Rio de Janeiro, causando prejuízo na baixada fluminense, da ordem de 50 a 90\% (Nascimento, 1980). Também Vasconcellos et al. (1980), relata que O. praelonga constitui-se numa das principais pragas da citricultura carioca, trazendo não só o prejuízo financeiro, como também o desestímulo, levando assim o abandono desta prática agrícola pelo citricultor.

De acordo com Teixeira et al. (2001), a cochonilha $O$. praelonga está disseminada nos Estados da Bahia, Sergipe, Rio de Janeiro, Rio Grande do Sul, Pará, Pernambuco e São Paulo. 
Por suportar grandes variações climáticas e devido à ausência de barreiras orográficas, Puzzi \& Camargo (1963), consideraram a possibilidade de que $O$. praelonga viria a ser uma praga de importância nas zonas citrícolas do Estado de São Paulo e que o Vale do Paraíba seria uma via natural de entrada do inseto.

No Estado de São Paulo, O. praelonga foi constatada pela primeira vez no município de Severínia, região citrícola de Bebedouro, por Gonçalves \& Cassino (1978).

De acordo com o Fundecitros, está aumentando a incidência de $O$. praelonga nas regiões sul e centro do estado de São Paulo, que antes predominava nas regiões norte e noroeste.

Além dos prejuízos proporcionados a produção citrícola dos Estados de São Paulo e Rio de Janeiro, esta praga constitui-se em uma séria ameaça a citricultura do Nordeste brasileiro, em função do grande número de plantas hospedeiras e da alta capacidade de reprodução (Carvalho et al., 1998).

Nos períodos de seca (maio a setembro) as infestações por $O$. praelonga são mais intensas, chegando a provocar a morte da planta. Nos períodos de novembro a março há um decréscimo na ocorrência da praga, motivada pelo aumento da temperatura e da umidade, que favorecem os agentes de controle natural da praga (Gomes, 1954; Viegas et al., 1995). O controle natural referido por esses autores é propiciado, principalmente, por fungos entomopatogênicos sendo Verticillium lecanii a espécie mais comum.

Segundo Lima (1980) os danos diretos ocorrem quando O. praelonga ataca as plantas de citros, inoculando substâncias toxicogênicas que retardam o desenvolvimento das mesmas, e promovem a queda prematura dos frutos, tornando-os "aguados", de tamanho reduzido e com baixos teores de açúcares e ácidos. Suas excreções açucaradas ("honeydew”) servem de substrato para o desenvolvimento do fungo Capnodium sp., que reveste folhas e frutos (Figura 1), diminuindo, provavelmente, a taxa de fotossíntese e transpiração, causando assim danos indiretos à cultura. (Robbs, 1947; Lima, 1981; Prates, 1987; Cassino et al., 1991, 1993 e Nascimento et al., 1993; Guirado et al., 2001). 
A floricultura é outra atividade agrícola afetada pelos danos desta cochonilha, onde inúmeras plantas servem de hospedeiro (Anexo A). Neste segmento agrícola, o controle de pragas é tratado com bastante cuidado pelos produtores, pois lotes que apresentam danos causados por insetos perdem o seu valor no momento da comercialização (Tamai et al., 2000).

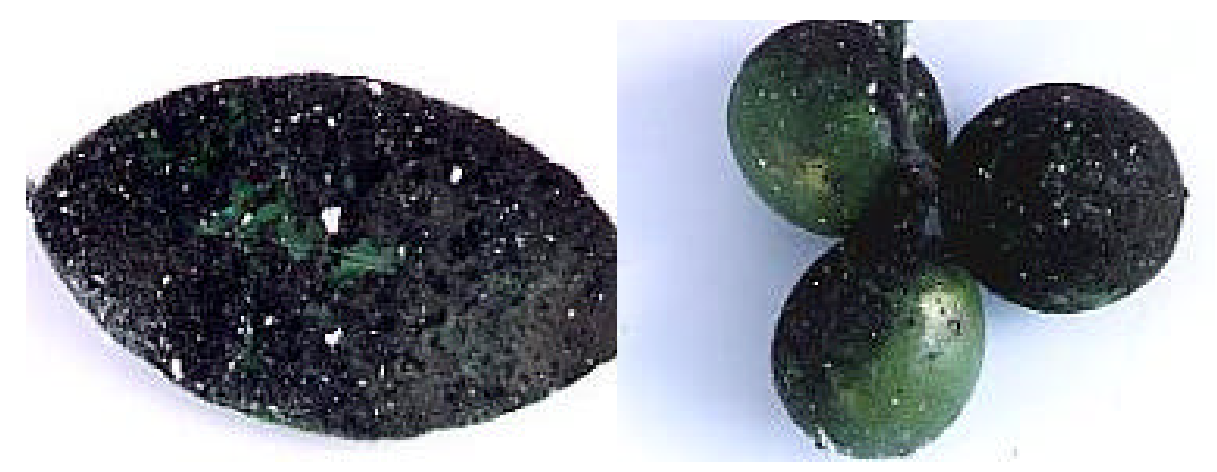

Figura 1- Folhas e frutos de citros infestados por Orthezia praeloga com fumagina

\subsection{Orthezia praelonga}

O. praelonga apresenta acentuado dimorfismo sexual. Quando bem desenvolvida, a fêmea mede cerca de $2,5 \mathrm{~mm}$ e tem o corpo coberto de placas de cera branca; duas placas salientes cobrem a cabeça na parte posterior do corpo. Na margem do corpo, estão localizadas diversas placas estreitas que se estendem para trás e que aumentam em comprimento até a região anal. Com o ovissaco totalmente formado, este inseto pode atingir 4,5mm (Suplicy Filho et al., 1983). Em estudos realizados por Vasconcelos et al. (1980), foi observada uma produção média de 210 nêanides por fêmea em trinta dias.

Os machos e as fêmeas são semelhantes, mas a partir do segundo estádio os machos dirigem-se para galhos, troncos ou solo, onde reunidos em colônias, evoluem para uma fase intermediária, semelhante a um pupário, envolvido por inúmeros 
filamentos de cera, de onde emergem os adultos. Estes são menores, com cabeça, tórax e abdome bem definidos, apresentando apenas duas asas e uma cauda branca alongada, formada de fios de cera (Prates, 1980). As fêmeas adultas que se desenvolvem nos meses mais frios, em cerca de 50 dias, apresentam o dorso abaulado, com duas pequenas áreas esverdeadas e sem cera (Prates, 1980).

Uma vez atingida a fase adulta, as fêmeas de $O$. praelonga começam a ovipositar continuamente e em grande quantidade no interior do ovissaco. Este é formado pela união de bastonetes alongados de cera, de coloração branca, com uma curvadura acentuada para cima. Dentro desta estrutura há a deposição dos ovos e o desenvolvimento inicial das neânides. Posteriormente, estas muito ativas, procuram um lugar para se fixarem, de preferência na parte inferior da folha (Negri, 1983; Prates \& Pinto, 1986). Inicialmente, a infestação limita-se quase que exclusivamente às folhas mais novas, localizadas na ponta dos galhos, e posteriormente toda a planta torna-se infestada (Gonçalves, 1963).

\subsection{Controle químico de Orthezia praelonga}

A chave do manejo da ortézia é o monitoramento feito pelos pragueiros, ou seja, a detecção do foco inicial ainda restrito a uma só planta e o controle da reboleira em torno dessa planta (Gravena, 2002).

Como a incidência da $O$. praelonga é maior em períodos secos, nessa época devem ser feitas inspeções mais criteriosas, realizando o seu controle assim que detectada no pomar. Nos pomares onde se observa, pela primeira vez, focos dessa praga, o combate deve ser imediato, tratando-se não apenas as plantas afetadas, como também as vizinhas e a vegetação rasteira existente nas imediações (CATI, 1997).

O controle químico desta praga é feito pela utilização de inseticidas sistêmicos, à base de aldicarb e dimetoato ou também pelo uso de fosforados, à base de paration (CATI, 1987). 
As reinfestações dos pomares tratados são influenciadas pelo transporte de neânides de primeiro e segundo instares pelo vento, por foresia em dípteros e pelo próprio movimento do inseto (Lima et al., 1980).

Segundo Lima \& Nakano, citado por Gravena et al. (1993) e Nascimento et al. (1993), são duas as principais dificuldades encontradas no controle químico da cochonilha: grande quantidade de hospedeiros e presença do ovissaco, que protege os ovos das pulverizações, propiciando futuras reinfestações nos pomares.

\subsection{Agentes de controle biológico}

O uso intensivo de agroquímicos tem causado diversos problemas, entre eles pode-se citar a resistência de pragas a inseticidas, exigindo um aumento da concentração e do número de aplicações. Esse fato concorre para a contaminação do solo, da água, da planta, do homem e de todos os microrganismos vivos e inimigos naturais que fazem parte do agroecossistema. Esses problemas têm reforçado a necessidade de adoção de um manejo mais racional, entre as práticas preconizadas podemos destacar a utilização do controle biológico (Robbs \& Bittencourt, 1998; Alves et al., 2001).

Atualmente, o uso do controle biológico vem assumindo importância cada vez maior dentro de programas de manejo integrado de pragas, num momento em que se discute a produção integrada rumo a uma agricultura sustentável (Parra et al., 2002). Para Vendramim (2002), o sistema mais adequado para o controle de pragas baseia-se no manejo integrado com a utilização de métodos harmoniosos de diferentes técnicas, em consonância com princípios ecológicos, econômicos e sociais com o objetivo de manter os organismos-praga abaixo do nível de dano econômico.

\subsubsection{Parasitóide e predadores}

Segundo Prates (1980), os inimigos naturais de O. praelonga, são: Gitona brasiliensis (Diptera: Drosophilidae) e Scymnus sp. (Coleoptera:Coccinellidae) que 
predam os ovos nos ovissacos; Ambracius dufourei (Hemiptera: Miridae), Azya luteipes (Coleoptera: Coccinellidae) e Crysopa sp. (Neuroptera: Crhysopidae), que predam jovens e adultos.

Em estudos de levantamento de inimigos naturais de Orthezia spp. realizados por Bobadilla et al.(1999) no norte do Chile (Vale do Azapa e Província de Parinacota) foram detectados: Gitona sp (Diptera: Drosophilidae); Melaleucopis sp (Diptera: Chamaemyiidae); Hyperspis annexa Lê Conte (Coleóptera: Coccinellidae); Scymnus spp (Coleoptera: Coccinellidae); Chrysopa sp (Neuroptera: Chrysopidae).

Observações realizadas por Pinto (2002), em pomares comerciais de citros da fazenda Citropar, foi constatado que em talhões altamente infestados por $O$. praelonga, a praga foi totalmente controlada pela mosca Gitona brasiliensis.

De ocorrência natural em pomares cítricos da Bahia e Sergipe, o caracol rajado (Oxystyla pulchella Spix, 1827) apresenta-se como inimigo natural capaz de controlar eficientemente $O$. praelonga, com a vantagem de também eliminar a vegetação epífita, refúgio natural de cochonilhas (Cruz et al., 1999).

\subsubsection{Fungos entomopatogênicos}

O uso de microrganismos para o controle de pragas representa atualmente um avanço ecológico para solucionar problemas ocasionados pelo emprego indiscriminado de inseticidas. Sendo que os grupos mais importantes são os fungos, bactérias, vírus, protozoários, nematóides, rickétsias e micoplasma. Dentre estes agentes biológicos de controle de insetos, os fungos causam cerca de $80 \%$ das enfermidades (Alves, 1998).

No que diz respeito à importância de fungos entomopatogênicos para o controle de $O$. praelonga, trabalhos conduzidos por Viègas et al. (1995) ao avaliarem a patogenicidade dos fungos Beauveria bassiana, Colletotrichum gloeosporioides e Metarhizium anisopliae para ninfas de segundo e terceiro ínstar de O. praelonga, observaram que os dois primeiros são os mais promissores para o controle deste inseto. 
Sabe-se também que Aschersonia aleyrodis ataca cochonilhas e as moscasbrancas Dialeurodes citri e D. citrifolii. O fungo coloniza a fase imóvel dessas pragas, deixando-as com coloração rósea-avermelhada (Alves et al., 2001).

Em observações realizadas em pomares comercias de citros, Prates (1980) relata a ocorrência dos fungos Colletotrichum gloeosporioides, Verticillium lecanii e Cladosporium herbarum var. aphidicola em O. praelonga.

Existem também outras espécies de fungos entomopatogênicos que são relatados em populações de O. praelonga. Gonçalves (1963) verificou o parasitismo deste inseto por Fusarium sp., Verticillium lecanii e Cladosporium sp., reduzindo populações de $O$. praelonga para níveis não econômicos.

O fungo Verticillium lecanni também ocorre naturalmente sobre pulgões e outras cochonilhas. Este patógeno tem causado epizootias em população de Coccus viridis, mantendo a população dessa praga em níveis de danos não-econômicos (Alves et al., 2001).

No Estado do Maranhão, Lourenção et al. (2001) relataram a ocorrência de epizootias de V. lecanii em campo, sobre ninfas de diferentes estágios de B. tabaci biótipo B, reduzindo drasticamente as populações deste inseto.

Excelentes resultados têm sido obtidos utilizando o fungo entomopatogênico Colletotrichum gloeosporioides, identificado por Robbs em 1947, sobre a cochonilha $O$. praelonga (Prates, 1980).

Recentemente, Cesnik et al. (1996) obtiveram redução significativa na infestação desta cochonilha quando aplicaram uma suspensão de conídios de $C$. gloeosporioides (isolado Orthezia), em pomares citrícolas na região de Limeira-SP. Neste trabalho, o patógeno foi aplicado na concentração de 1 litro de uma suspensão contendo 1,34 x $10^{6}$ conídios/mL por planta. Observou-se depois de 35 dias da aplicação do patógeno, redução de 43 a $82 \%$ no número de insetos encontrados nas folhas das plantas tratadas. Após 70 dias da aplicação, a redução na população da praga atingiu de 85 a $96 \%$.

A eficiência do isolado de C. gloeosporioides (CTAA-AM/3), no controle biológico da $O$. praelonga, foi confirmada num experimento instalado com laranja 
'Pêra' de 6 anos de idade, mediante a aplicação de suspensão de conídios $\left(1,5 \times 10^{7}\right.$ conídios/mL), com pulverizador costal. Ao final de 7 dias da aplicação, obteve-se uma mortalidade de 84,9\% e, aos 15 dias, o patamar de 100\% (Rosamiglia, 1998). Entretanto, testes realizados em laboratório para o controle alternativo de $O$. praelonga $\left(2^{\circ}\right.$ e $3^{\circ}$ ínstares), com C. gloeosporioides, mostraram 41,35\% de mortalidade do inseto após 21 dias da aplicação (Viegas et al. 1995). Esse resultado foi obtido quando utilizou-se o fungo entomopatogênico com 150 dias de conservação $\left(21^{\circ} \mathrm{C}-27^{\circ} \mathrm{C}\right.$ e $75 \%$ de UR).

O fungo C. gloeosporioide, e outras espécies de fungos, apresentam grande variabilidade genética, podendo ser encontrados isolados entomopatogênicos e até fitopatogênicos. A caracterização morfológica e bioquímica de diferentes linhagens deste fungo foi realizada por Rosamiglia \& Melo (1996), tendo sido encontrado perfis diferenciados para as linhagens entomopatogênicas isoladas de O. praelonga, em plantios comerciais de citros no Estado de São Paulo e Rio de Janeiro, e para linhagens fitopatogênicas.

Em testes de eficiência do fungo entomopatogênico Cladosporium cladosporioides em campo, na concentração de 5,2 × $10^{5}$ esporos/mL, foi obtido uma redução de $93 \%$ na população de $O$. praelonga no $39^{\circ}$ dia após o tratamento (Sanches, 2003).

Em trabalhos de levantamento de inimigos naturais de Orthezia spp. realizados por Bobadilla et al. (1999), foram encontrados exemplares deste inseto infectados por fungo. A identificação deste patógeno está sendo feita na Universidade de Valparaíso, no Chile. Este entomopatógeno foi isolado e cultivado em meio artificial (Batata-Dextrose-Ágar) para realização de testes em laboratório com o objetivo de confirmar sua eficiência. Os ensaios preliminares indicam que 100\% das ninfas e 52\% dos adultos foram infectados por este fungo.

De acordo com Robbs (1973) e Cassino et al. (1975), os únicos inimigos naturais eficientes e que ocorrem em quase todos os anos, na maioria das áreas citrícolas, reduzindo consideravelmente a população do inseto são: $V$. lecanii e $C$. gloeosporioides. 


\subsection{Seleção de isolados em programas de controle microbiano}

No desenvolvimento de um programa de controle microbiano de pragas é de fundamental importância a utilização de linhagens e/ou isolados apropriados do agente biológico. Para isso, é necessário possuir um "bom banco de isolados", devidamente preservado, e com variabilidade genética comprovada, para então, se iniciar o programa a partir da seleção dos materiais promissores, visando explorar toda biodiversidade disponível.

Entre as qualidades desejadas para um fungo entomopatogênico, Alves (1998) e Frigo \& Azevedo (1986) destacam-se às seguintes: alta eficiência no controle, grande capacidade de disseminação, resistência à condições adversas, além de qualidades industriais como ótima produção de conídios e taxa de crescimento elevada, entre outras. Essas qualidades podem existir naturalmente em linhagens selvagens ou serem conseguidas por indução de mutação.

A variabilidade genética entre isolados de uma mesma espécie de fungo, é amplamente relatada na literatura. Muitos dos trabalhos conduzidos para espécies de interesse entomológico foram feitos com M. anisopliae e B. bassiana, em muitos casos, como testes iniciais visando a sua utilização em programas de controle microbiano. Este procedimento tem sido empregado há muitos anos pelo Laboratório de Patologia e Controle Microbiano de Insetos da ESALQ/USP, sendo na maioria dos casos, encontrado materiais promissores para o controle de diferentes espécies de insetos (Moino Júnior, 1993; Vieira et al., 1993; Almeida et al., 1997; Tamai, 1997; Manzini et al., 1998; Lopes, 1999; Tanzini, 2002). Os resultados destas pesquisas evidenciaram a grande variabilidade genética existente entre os fungos entomopatogênicos, sendo assim importante e necessária à realização de uma seleção de isolados altamente patogênicos para determinada praga.

Assim, Moino Júnior (1993), ao avaliar a patogenicidade de 72 isolados dos fungos $B$. bassiana e $M$. anisopliae para três espécies de insetos que atacam grãos armazenados no Brasil (Coleoptera: Curculionidae), observou uma grande variação nas mortalidades obtidas, encontrando isolados que foram totalmente ineficientes para estas 
pragas e outros que causaram $100 \%$ de mortalidade. Variações também foram observadas nos trabalhos de Vieira et al. (1993) e Almeida et al. (1997) ao avaliarem a patogenicidade de mais de uma centena de isolados dos mesmos fungos, para Periplaneta americana (L.) e ao cupim Heterotermes tenuis (Hagen), respectivamente. No primeiro caso, foi possível selecionar 12 isolados de $M$. anisopliae e 21 isolados de B. bassiana que provocaram $100 \%$ de mortalidade de $P$. americana. Para $H$. tenuis, foi possível selecionar o isolado ESALQ-634 de B. bassiana, que causa alta mortalidade do inseto e apresenta boa produção de conídios em diversos meios de cultura e sobre o inseto teste.

De forma semelhante aos trabalhos referidos anteriormente, Lecuona et al. (1996) encontraram grandes diferenças na patogenicidade de 21 isolados brasileiros e argentinos de B. bassiana para larvas de Diatraea saccharalis (Fabricius). Sendo que a mortalidade variou de 50 a $90 \%$ de larvas, sendo de forma geral, os isolados brasileiros menos patogênicos (50 a 70\% de mortalidade) do que os argentinos (60 a $90 \%$ de mortalidade). Feng \& Johnson (1990) testaram seis isolados de B. bassiana a Diuraphis noxia (Mordvilko) e obtiveram uma variação na mortalidade de 10 a $75 \%$ e de 40 a 95\%, nas concentrações de $5 \times 10^{5}$ e $1 \times 10^{7}$ conídios $/ \mathrm{mL}$, respectivamente. Moorhouse et al. (1993a,b) avaliaram a patogenicidade de 19 isolados de Metarhizium spp. a larvas de Otiorhynchus sulcatus (Fabricius) e obtiveram valores de $\mathrm{TL}_{50}$ variando entre 6,1 a 8,7 dias.

Esta diferença de patogenicidade entre isolados também tem sido documentada para outros entomopatógenos como V. lecanii, Peacilomyces fumosoroseus e Nomuraea rileyi (Farlow) quanto à $\mathrm{TL}_{50}$ e a mortalidade total (Jackson et al., 1985; Maniania \& Fargues, 1992).

Tanzini (2002), avaliando a patogenicidade de 60 isolados de 8 espécies de entomopatógenos no controle de Leptopharsa heveae, obteve mortalidade que variou de 23 à $100 \%$.

Trabalhos como esses permitem selecionar materiais promissores, como os isolados ESALQ-1037 de M. anisopliae e ESALQ-447 de B. bassiana, ambos obtidos de Solenopsis sp., e mantidos no banco de patógenos da ESALQ/USP. No caso do isolado 
ESALQ-1037, bioensaios realizados demonstram o seu grande potencial para o controle de diferentes espécies de insetos, como larvas de Culex quinquefasciatus Say e $D$. saccharalis, além de adultos de Blatella germanica (L.), Solenopsis saevissima (Smith) e térmitas (H. tenuis e Cornitermes cumulans (Kollar)) (Alves et al., 1997).

Em trabalho visando selecionar entomopatogênicos para o controle Dysmicoccus texensis Tinsley, Carvalho (2003) obteve testando 81 isolados de fungos e 4 de nematóides variação na mortalidade de 24 a $64 \%$ e de 54 a 78\%, respectivamente.

Garcia et al. (2000), trabalhando com 16 isolados de 6 espécie de fungos entomopatogênicos não obtiveram resultados promissores nos ensaios de seleção visando ao controle de $O$. praelonga. Estes autores sugeriram a necessidade da realização de novos testes, utilizando um maior número de isolados de diferentes espécies de fungos, visando identificar entomopatógenos patogênicos a este inseto. 


\section{MATERIAL E MÉTODOS}

O presente trabalho foi desenvolvido no Laboratório de Patologia e Controle Microbiano de Insetos, do Departamento de Entomologia, Fitopatologia e Zoologia Agrícola da Escola Superior de Agricultura "Luiz de Queiroz", Universidade de São Paulo (ESALQ/USP), em Piracicaba-SP.

\subsection{Criação e manutenção de Orthezia praelonga em laboratório}

Para que fosse possível a realização dos bioensaios foi necessário o estabelecimento de uma criação de $O$. praelonga. Esta foi realizada em mudas envasadas de laranja das variedades Pêra e Valência, e em diversas espécies de plantas ornamentais. Após a infestação das mudas pelos insetos, estas permaneceram em casa de vegetação, com o objetivo de se promover o desenvolvimento adequado do inseto, da planta hospedeira e evitar contaminação por inimigos naturais.

As mudas utilizadas na criação foram renovadas à medida que as mesmas perdiam seu vigor e sanidade. Foram mantidas na criação de quinze a vinte mudas infestadas, constituindo-se assim a colônia estoque da cochonilha.

Todos materiais utilizados na criação e bioensaios (mudas e tubetes) foram obtidos por meio de contatos estabelecidos entre a Eng. Agr. Heloísa Sabino Prates (CDA/SAA-Campinas/SP) e viveiristas da região de Limeira-SP. 


\subsection{Isolados dos fungos}

Foram utilizados isolados dos fungos B. bassiana, B. brongniartii, $C$. cladosporioides, M. anisopliae, Sporothrix sp. Paecilomyces, fumosoroseus P. lilacinus, V. lecanii (Figura 1), provenientes de diferentes localidades do Brasil, obtidos a partir de amostras de solo e de insetos infectados. Além desses materiais foi testado o produto comercial Boveril®, formulado com o isolado ESALQ-447 de B. bassiana.

Os isolados encontram-se armazenados no Banco de Patógenos do Laboratório de Patologia e Controle Microbiano de Insetos da ESALQ/USP, em freezer a $-12^{\circ} \mathrm{C}$ na forma de conídios puros. Por ocasião dos testes, os fungos foram repicados e multiplicados em meio de cultura M.C. (meio completo - 0,36 g de $\mathrm{KH}_{2} \mathrm{PO}_{4}$; $1,05 \mathrm{~g}$ de $\mathrm{NaHPO}_{4} .7 \mathrm{H}_{2} \mathrm{O} ; 0,60 \mathrm{~g}$ de $\mathrm{MgSO}_{4} .7 \mathrm{H}_{2} \mathrm{O} ; 1,00 \mathrm{~g}$ de $\mathrm{KCl} ; 10,00 \mathrm{~g}$ de glucose; $1,58 \mathrm{~g}$ de $\mathrm{NaNO}_{3} ; 5,00 \mathrm{~g}$ de Extrato de levedura; 20,00 g de Agar; 1000,00 mL de Água destilada), previamente autoclavado a $120^{\circ} \mathrm{C}$ por 20 minutos. As placas de Petri e demais vidrarias foram esterilizadas com calor seco em estufas a $180^{\circ} \mathrm{C}$ por um período de 8 horas.

A repicagem foi feita colocando-se uma amostra de conídios puros em placa de Petri contendo meio de cultura estéril. Estes foram então espalhadas por toda a placa com alça de Drigalsky. Estas duas etapas foram realizadas em câmara de fluxo laminar, sob condições assépticas. Em seguida as placas foram então mantidas durante 10 dias em câmara B.O.D. a $26 \pm 0,5^{\circ} \mathrm{C}$ e 12 horas de fotofase, para o crescimento e esporulação do fungo. 


\begin{tabular}{|c|c|c|c|}
\hline Espécie/Produto & Isolado & Procedência & Hospedeiro \\
\hline Beauveria bassiana & 307 & Araras-SP & Diatraea saccharalis \\
\hline Beauveria bassiana & 447 & Cuiabá-MT & Solenopsis invicta \\
\hline Beauveria bassiana & 489 & Desconhecida & Hemileucidae (Lepidoptera) \\
\hline Beauveria bassiana & 494 & Piracicaba-SP & Dorcadocerus barbatus \\
\hline Beauveria bassiana & 868 & Goiânia-GO & Formicidae (Hymenoptera) \\
\hline Beauveria bassiana & 969 & Piracicaba-SP & Blatella germanica \\
\hline Beauveria bassiana & 1248 & Bebedouro-SP & Cigarrinha \\
\hline Beauveria bassiana & PL-63 & Piracicaba-SP & Solenopsis sp. \\
\hline Beauveria bassiana & 448 & Cuiabá-MT & Solenopsis invicta \\
\hline Beauveria bassiana & 292 & Capivari-SP & Anthonomus grandis \\
\hline Beauveria bassiana & Cpac-32 & Rio Grande do Norte & Orthezia sp. \\
\hline Beauveria bassiana & 957 & Piracicaba-SP & Solenopsis sp. \\
\hline Beauveria bassiana & 620 & Goiânia-GO & Nezara viridula \\
\hline Beauveria bassiana & 1258 & Caçú-GO & Leptopharsa heveae \\
\hline Beauveria bassiana & 760 & Alcantara-SC & Conitermes cumulans \\
\hline Beauveria sp. & 677 & Cuiabá-SP & Solenopsis sp. \\
\hline Beauveria $\mathrm{sp}$ & 590 & Piracicaba-SP & Solenopsis saivissima \\
\hline Beauveria bassiana & 617 & Goiânia-GO & Pentatomidae \\
\hline Beauveria bassiana & 500 & Blanco Poso-ARG & Diabrotica speciosa \\
\hline Beauveria bassiana & 1197 & Corumbá-MS & solo \\
\hline Beauveria brongniatii & 1147 & Santa Catarina & solo \\
\hline Beauveria brongniatii & 210 & Araras-SP & Diatraea saccharalis \\
\hline Beauveria brongniatii & 1251 & Lima-Peru & \\
\hline Beauveria brongniatii & 478 & Cuiabá-MT & Solenopsis invicta \\
\hline Boveril $\AA$ & & Itaforte-Bioprodutos & \\
\hline Metarhizium anisopliae & E-9 & Boca da Mata-AL & Mahanarva posticata \\
\hline Metarhizium anisopliae & 319 & Goiana-PE & Mahanarva posticata \\
\hline Metarhizium anisopliae & 860 & Piracicaba-SP & Macrospis sp. \\
\hline
\end{tabular}

Figura 2- Procedência e hospedeiro dos fungos entomopatogênicos utilizados nos bioensaios com Orthezia praelonga 


\begin{tabular}{|c|c|c|c|}
\hline Espécie/Produto & Isolado & Procedência & Hospedeiro \\
\hline Metarhizium anisopliae & PL-43 & Fleixeira del Estado-AL & Mahanarva posticata \\
\hline Metarhizium anisopliae & CB-345 & & \\
\hline Metarhizium anisopliae & CB-348 & & \\
\hline Metarhizium anisopliae & 1022 & Piracicaba-SP & Phyllophaga sp. \\
\hline Metarhizium anisopliae & 1104 & São João do Piauí-PI & Solo \\
\hline Metarhizium anisopliae & 1037 & Porto Alegre-RS & Solenopsis sp. \\
\hline Metarhizium anisopliae & 1220 & não identificada & Cigarrinha do citrus \\
\hline Paecilomyces fomosoroseus & 1296 & Jaboticabal-SP & Bemisia tabaci \\
\hline Paecilomyces fumosoroseus & 1200 & Amélia Rodrigues-BA & Mahanarva fimbriolata \\
\hline Paecilomyces lilacinus & 581 & Cuiabá-MT & Solenopsis invicta \\
\hline Verticillium lecanii & 870 & Piracicaba-SP & Coccus viridis \\
\hline Verticillium $\mathrm{sp}$. & 972 & Piracicaba-SP & Coccus viridis \\
\hline Verticillium lecanii & 1241 & Piracicaba-SP & Pulgão \\
\hline Verticillium lecanii & 949 & Polônia & Triraleurodes vaporarium \\
\hline Verticillium $\mathrm{sp}$. & 941 & Piracicaba-SP & Cochonilha \\
\hline Verticillium lecanii & 1254 & Bolívia & \\
\hline Verticillium sp. & 1242 & Piracicaba-SP & tripes \\
\hline Verticillium lecanii & 950 & Indonésia & Coccus viridis \\
\hline Verticillium lecanii & 1300 & Bebedouro-SP & Orthezia praelonga \\
\hline Verticillium lecanii & 1239 & Monte Azul Paulista-SP & Cigarrinha \\
\hline Cladosporium cladosporioides & CLA & Piracicaba-SP & Orthezia praelonga \\
\hline Sporothrix sp. & 1224 & Brasília-DF & Leptopharsa heveae \\
\hline Sporothrix sp. & 1227 & Itiquira-MT & Leptopharsa heveae \\
\hline
\end{tabular}

Figura 2- Procedência e hospedeiro dos fungos entomopatogênicos utilizados nos bioensaios com Orthezia praelonga 


\subsection{Bioensaios de seleção}

Nestes testes, foram utilizadas mudas de limão-cravo de aproximadamente $40 \mathrm{~cm}$ de altura, acondicionadas em tubetes plásticos. A infestação das mudas com $O$. praelonga foi realizada colocando-se sobre elas, folhas altamente infestadas pelo inseto. A medida que as folhas infestadas desidratavam, os insetos se desprendiam das mesmas e se dirigiam para as folhas tenras das mudas. Foram mantidos de 20 a 50 insetos por tubete, sendo o excesso retirado, evitando-se assim uma grande variação populacional entre as diferentes repetições.

As cochonilhas contidas nas mudas foram inoculadas com o patógeno por meio de pulverização de $5 \mathrm{~mL}$ de suspensão por muda, na concentração de $1 \times 10^{8}$ conídios/mL, preparada com água destilada e espalhante adesivo (Tween $40^{\circledR}$ ) a $0,01 \%$. Foi utilizada uma concentração alta para a possível discriminação da patogenecidade dos diferentes gêneros e isolados de fungos.

A aplicação foi feita com um pulverizador com pressão constante de 0,5 libras/segundo. Após a inoculação, as mudas foram colocadas em câmara de fluxo laminar, por aproximadamente 5 minutos para secagem do líquido aplicado. Em seguida as mudas foram mantidas em estufas B.O.D. $\left(25 \pm 2^{\circ} \mathrm{C}, 60 \pm 10 \%\right.$ UR e 12 horas de fotofase).

Para cada tratamento foram utilizadas quatro repetições, sendo cada repetição representada por um muda. A avaliação dos bioensaios foi feita 12 dias após a inoculação do patógeno, contando-se o número total de insetos vivos e mortos por muda. Os insetos mortos foram lavados em álcool $70 \%$ e, posteriormente, colocados em câmara úmida para confirmação da morte pelo patógeno. A mortalidade observada foi corrigida conforme a fórmula proposta por Abbot (1925). 


\subsection{Produção de conídios dos isolados selecionados em arroz pré-cozido pelo método de bandejas}

Foram testados nesta etapa apenas os isolados mais virulentos selecionados anteriormente.

Inicialmente, esses isolados foram repicados em placas de Petri contendo meio de cultura M.C., previamente autoclavado a $120^{\circ} \mathrm{C}$ por 20 minutos. As placas com os conídios foram mantidas durante dez dias em câmara B.O.D. a $26^{\circ} \mathrm{C}$ e 12 horas de fotofase para o crescimento e esporulação do fungo. Decorrido este período, a placa foi raspada para retirada dos conídios e então, preparada uma suspensão 1 x $10^{8}$ conídios/mL com água estéril mais espalhante adesivo a $0,01 \%$.

Foram retirados $10 \mathrm{~mL}$ da suspensão de conídios para a inoculação de $300 \mathrm{~g}$ de arroz pré-cozido, contido em um saco plástico de polipropileno de $35 \mathrm{~cm}$ de comprimento por $22 \mathrm{~cm}$ de largura, fechado com duas dobras, grampeado, previamente esterilizado em autoclave a $120^{\circ} \mathrm{C}$ por 30 minutos e resfriado em condição ambiente.

A inoculação foi realizada em câmara de fluxo laminar, usando-se uma pipeta estéril de $10 \mathrm{~mL}$, agitando-se em seguida o saco plástico para uma distribuição uniforme dos conídios na massa de grãos. Cada isolado foi inoculado em quatro sacos plásticos.

Feita a inoculação, os sacos foram acondicionados em B.O.D. a $26^{\circ} \mathrm{C}$ e 12 horas de fotofase por três dias para a germinação dos conídios e crescimento de micélio. Decorrido este período, foram selecionados para cada isolado três sacos não contaminados com crescimento uniforme de micélio, que tiveram seu conteúdo adicionado em uma bandeja plástica de $46 \mathrm{~cm}$ de comprimento, $30 \mathrm{~cm}$ de largura e 11 $\mathrm{cm}$ de altura. As bandejas foram mantidas empilhadas em sala asséptica a $27 \pm 1^{\circ} \mathrm{C}$ e 16 horas de fotofase, por 16 dias. Após 7 dias essas bandejas foram cruzadas e mantidas empilhadas, permitindo assim uma maior ventilação entre elas e secagem mais rápida do arroz com fungo (Alves \& Pereira, 1989).

Depois de 16 dias, com o material contido na bandeja completamente seco, foi feita a retirada de cinco amostras de $10 \mathrm{~g}$ de arroz com fungo de cada bandeja, em locais de plena esporulação. Cada amostra foi adicionada a $100 \mathrm{~mL}$ de água estéril mais 
espalhante adesivo a $0,01 \%$, para a preparação de uma suspensão de conídios, a qual foi quantificada em câmara de Neubauer, tomando-se cinco amostras da suspensão.

Os valores obtidos nas contagens foram submetidos ao teste de Tukey para comparação entre médias de produção de conídios.

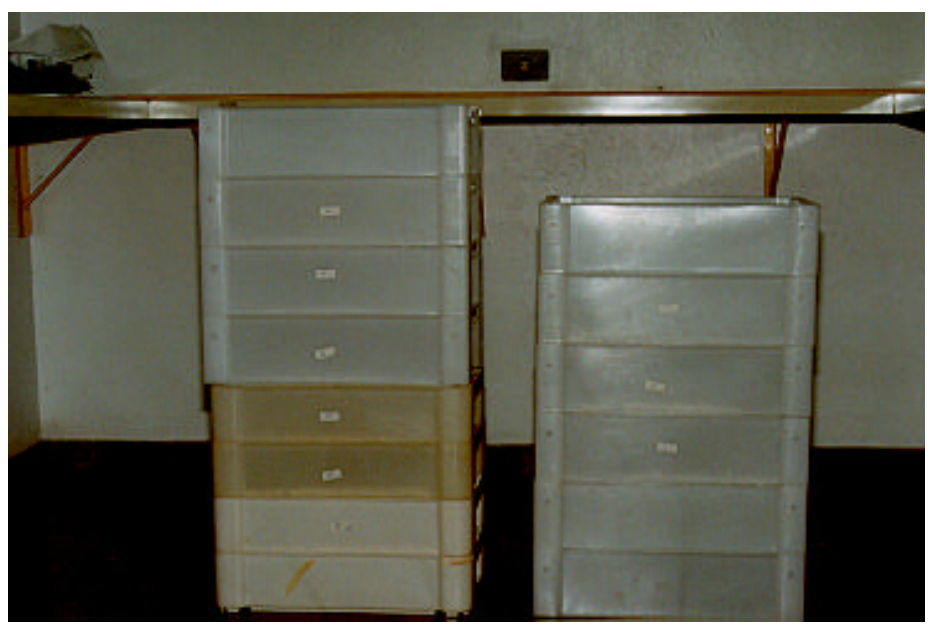

Figura 3- Produção de fungos entomopatogênicos pelo método de bandejas

\subsection{Produção de conídios dos isolados selecionados usando sistema de caixa com umidade forçada}

Nesta etapa testou-se os mesmos isolados utilizados na produção pelo método de bandejas.

O método de caixa com umidade forçada desenvolvido por Tanzini (2002) (Figura 4), consiste na utilização de um recipiente de plástico com $20 \mathrm{~cm}$ de largura, por $32 \mathrm{~cm}$ de comprimento e $25 \mathrm{~cm}$ de altura. A tampa da caixa possui dois orifícios de $0,7 \mathrm{~cm}$ de diâmetro para saída de ar. Na lateral inferior do recipiente foi montado um sistema de aeração constante resultando em fluxo positivo, gerado por uma bomba de ar, tipo aquário (marca Vigo-ar Super II) e distribuído por meio de válvulas e mangueiras com pedra porosa na extremidade. Na saída de ar da bomba foi instalado um filtro millipore 
$(0,2 \mu \mathrm{m})$, para impedir a entrada de contaminantes durante o processo de oxigenação. No fundo da caixa foi colocado 1 litro de água estéril com $2 \mathrm{~g}$ de antibiótico (streptomicina), formando uma lâmina d' água que, juntamente com o sistema de aeração por mangueiras, manteve o ambiente com umidade acima de $90 \%$.

O substrato utilizado foi o arroz esterilizado em autoclave a $120^{\circ} \mathrm{C}$ por 20 minutos em sacos plásticos de polipropileno, e que posteriormente foram inoculados em câmara de fluxo laminar. Utilizou-se $10 \mathrm{~mL}$ de suspensão para cada $300 \mathrm{~g}$ de arroz. Os sacos foram agitados manualmente para homogeneização do inóculo. O substrato de desenvolvimento do patógeno foi transferido para as caixas de produção (3 a 5 $\mathrm{Kg} /$ caixa), permanecendo apoiado em anteparo metálico a $2,5 \mathrm{~cm}$ de altura do fundo do recipiente. As caixas foram fechadas e mantidas em sala asséptica $\left(26 \pm 2{ }^{0} \mathrm{C}\right.$ e 12 horas de fotofase) durante cinco dias. A lâmina d'água presente no fundo foi retirada no terceiro dia após o inicio do experimento, por meio de uma abertura localizada no canto inferior do recipiente. A tampa da caixa de produção foi semi-aberta no quinto dia, visando favorecer a esporulação do patógeno e a secagem do substrato, permanecendo nesta condição por cinco dias.

Os valores obtidos foram submetidos ao teste de Tukey para comparação entre médias de produção de conídios. 


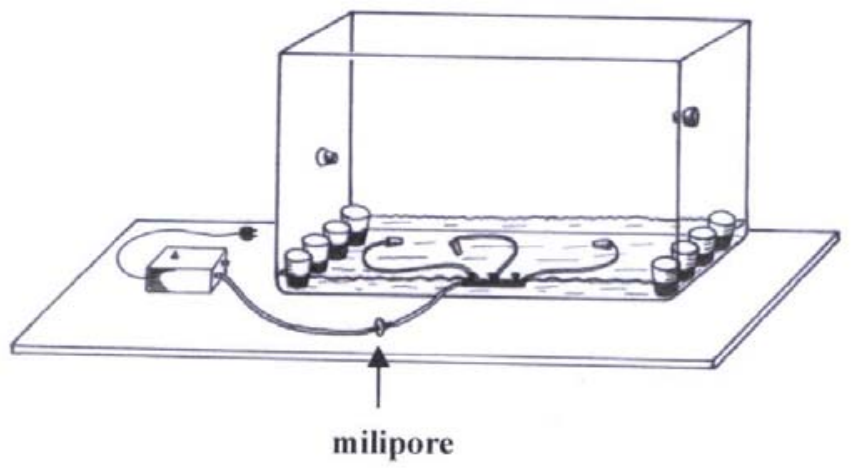

A

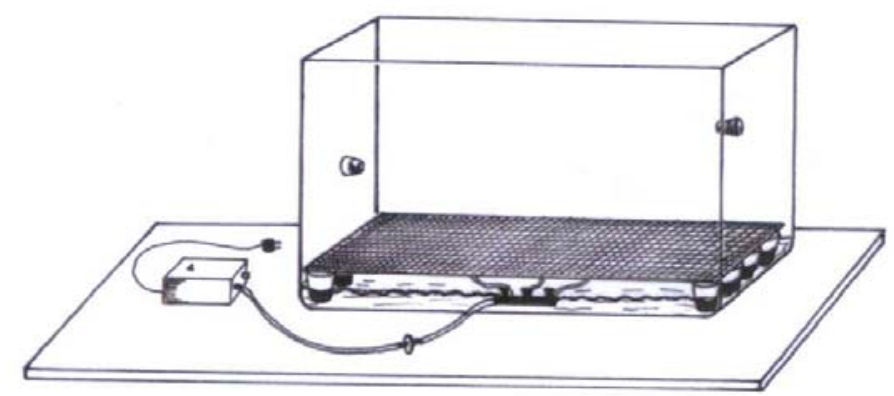

B

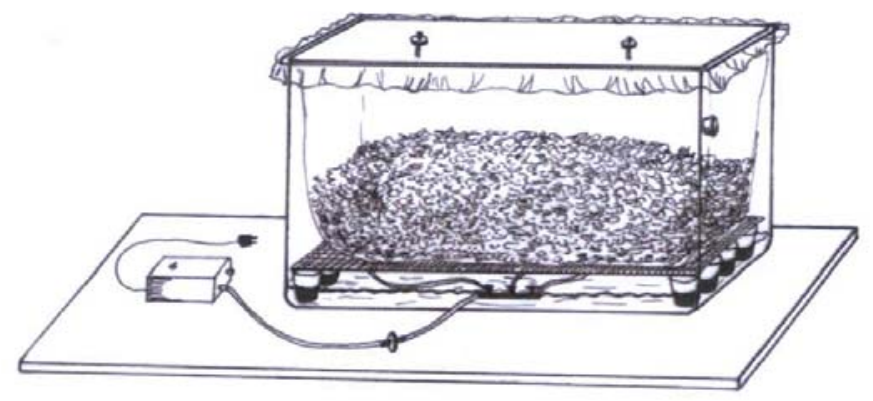

C

Figura 4 - Caixa de produção de fungos entomopatogênicos. A- Vazia com sistema de aeração e água. B- Com anteparo metálico e tela para suporte do substrato C- Com substrato inoculado 


\section{RESULTADOS E DISCUSSÃO}

\subsection{Criação e manutenção de Orthezia praelonga em casa-de-vegetação}

A metodologia proposta para o estabelecimento e manutenção de Orthezia praelonga em casa-de-vegetação mostrou-se bastante eficiente, na medida em que forneceu insetos sadios e em grande quantidade.

Embora mantida em local isolado, a criação foi alvo de ocorrência de dois agentes naturais de controle, sendo eles um Gastropoda e um entomopatógeno.

Assim, no decorrer do estudo, observou-se a ocorrência de um fungo de coloração preta sobre os insetos, que na maioria das vezes encontravam-se mortos ou moribundos. Com isso, foi realizada a coleta deste material e preparo de lâminas para visualização em microscopia ótica objetivando sua identificação. As imagens obtidas foram enviadas ao taxonomista Dr. Richard A. Humber da "Insect Mycologist \& Curator", USDA-ARS Collection of Entomopathogenic Fungal Cultures (ARSEF), o qual identificou o patógeno como sendo Cladosporium cladosporioides. A ocorrência desse microrganismo é freqüentemente relatada em pomares cítricos, porém sem apresentar importância significativa na redução da população desta praga (Prates, 1981). Entretanto, pesquisas recentes realizadas por Sanches (2003) constataram redução de $93 \%$ na população de $O$. praelonga $39^{\circ}$ dia após o tratamento com C. cladosporioides. Visto que há resultados conflitantes em relação à eficiência deste entomopatógeno, foi realizado o isolamento, produção e inclusão deste material na lista de isolados testados nesta pesquisa. 
Também foi observada na criação a presença de um grande número de caracóis, os quais proporcionaram uma redução significativa na população de ninfas e adultos da cochonilha. Este fato coincide com as pesquisa realizadas por Cruz et al. (1999) que obtiveram em laboratório uma redução de 41,93 \% de ninfas e 24,95\% dos adultos fornecidos ao caracol Oxystyla pulchella. Outros testes que mencionam taxas de consumo médio de $81 \%$ de ninfas e $62 \%$ dos adultos pelo caracol (Nascimento et al., 1993). Por apresentar esta elevada eficiência, Cruz et al. (1999), sugere que O. pulchella pode ser utilizado no manejo integrado de $O$. praelonga em pomares cítricos.

\subsection{Seleção de isolados mais virulentos}

Com exceção dos isolados ESALQ-972 e ESALQ-1300 de Verticillium lecanii, os demais fungos testados apresentaram baixa virulência ou foram não patogênicos a $O$. praelonga. Os resultados de mortalidade média de $O$. praelonga obtidos nos bioensaios com os isolados de fungos entomopatogênicos, estão apresentados na Figura 5.

Como pode-se observar a grande a maioria dos isolados testados mataram menos que $20 \%$ dos insetos tratados. Os fungos Beauveria brongniartii, Paecilomyces fumosoroseus, Paecilomyces lilacinus e Sporothrix sp. não são relatados na literatura como de ocorrência natural sobre a cochonilha.

Apesar de Beauveria bassiana ser uma espécie de ocorrência generalizada em todos os países e ser a mais freqüente sobre os insetos e em amostras de solo (Alves et al., 1998), os 16 isolados testados não foram patogênicos ou apresentaram baixa virulência. Este fato foi observado no campo por Prates (1981), onde esta relata a ocorrência do fungo, porém não reduzindo significativamente a população da praga.

Embora o fungo Metarhizium anisopliae tenha ampla ocorrência natural e possa ser encontrado em mais de 300 espécies de insetos das diferentes ordens (Alves et al., 1998), os 10 isolados testados não foram patogênicos a O. praelonga. Resultado semelhante foi obtido por Viegas et al. (1995), que não teve sucesso utilizando-se apenas 
um isolado de $M$. anisopliae em seus experimentos. No entanto, há necessidade de se testar um maior número de isolados de M. anisopliae para se avaliar o seu verdadeiro potencial no controle de $O$. praelonga. 
Figura. 5- Mortalidade corrigida de adultos de Orthezia praelonga após inoculação com isolados de fungos entomopatogênicos

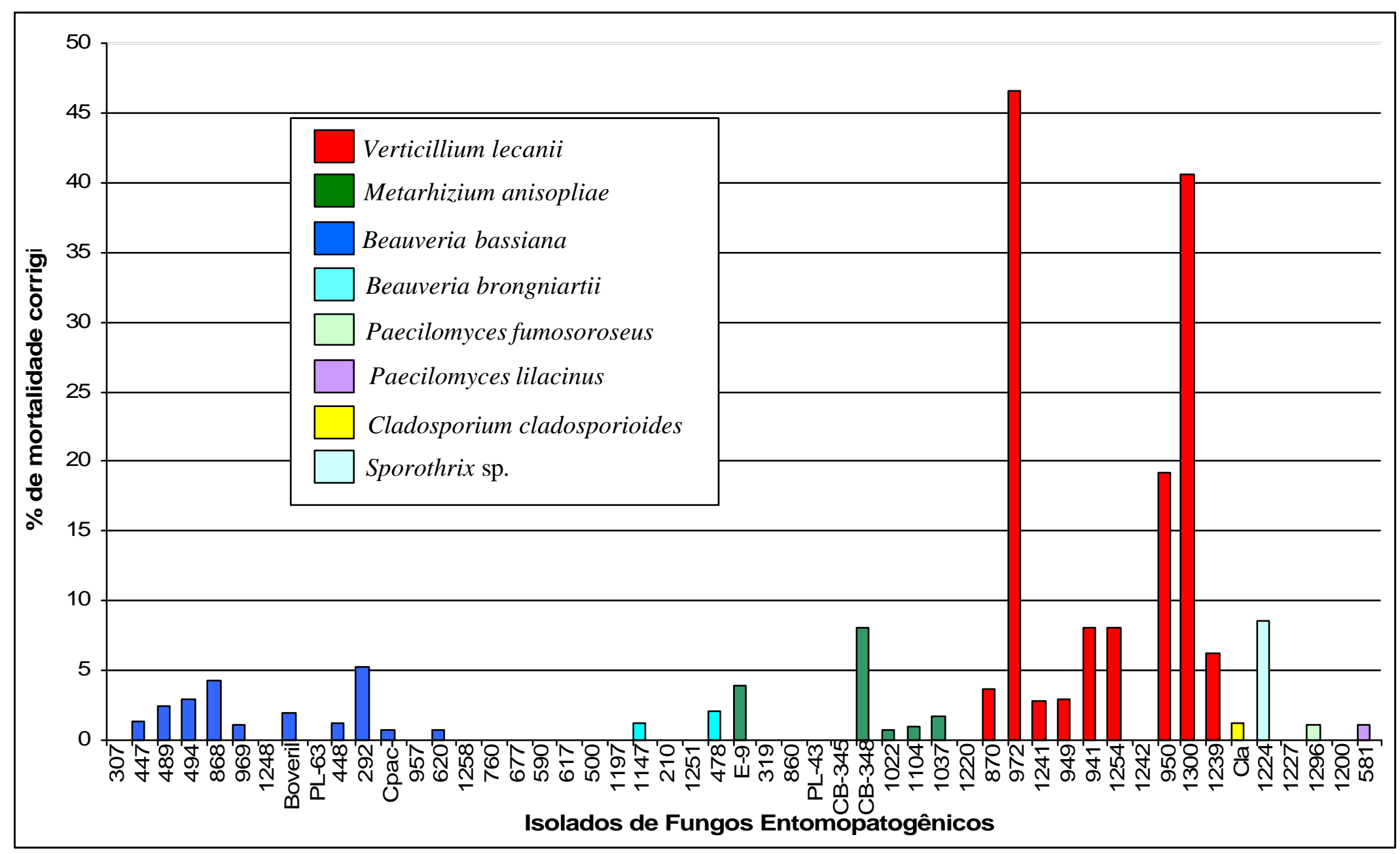


Diversos parâmetros podem influenciar o processo de ocorrência de doenças em insetos. Este fato pode dificultar a avaliação da patogenicidade e levar a uma baixa virulência dos entomopatógenos testados.

Desta forma, a não patogenicidade apresentada por parte dos isolados testados deve-se, provavelmente, a especificidade apresentada por algumas espécies de patógenos. Um exemplo desde caráter é o caso de Nomuraea rileyi, onde cerca de $90 \%$ de seus hospedeiros pertencem a ordem Lepidoptera (Alves et al., 1998), fato este que demonstra que existe, para alguns grupos, uma certa especificidade que faz com que um determinado isolado seja muito virulento para uma espécie de inseto e não seja para outra. Esta característica é considerada uma vantagem do controle microbiano em relação ao químico, pois mesmo quando os microrganismos são aplicados em altas concentrações, conseguem evitar alterações importantes no agroecossistema, por não afetarem parasitóides, predadores e polinizadores (Alves et al., 1998). Desta forma, o fato de grande parte dos isolados apresentarem resultados negativos é normal em trabalhos de seleção, e deve ser encarado como característica positiva do controle microbiano de insetos e não como uma premissa de que este tipo de controle seja inviável.

A barreira física proporcionada pela camada de cera existente no inseto faz com que grande parte do inóculo aplicado fique retido na mesma. Com isto, a porção que entra em contato com tegumento do inseto não é suficiente para promover o início do processo de infecção. Alguns estudos sugerem que existe um número mínimo de estruturas do patógeno necessárias para desencadear a doença em um inseto (Alves et al., 1998).

No caso de ninfas de mosca-branca, a cutícula produz lipídios de longas cadeias de ésteres, que formam uma barreira física para os conídios, prejudicando assim os processos de adesão, germinação e penetração (Buckner et al., 1999).

Em testes de seleção visando o controle de Dysmicoccus texenses Tinsley, cochonilha da raiz do coqueiro que possui uma camada cerosa e farinhenta que protege seu corpo, Carvalho (2003), obteve os melhores resultados usando nematóides pois este 
microrganismo além de penetrar pelo tegumento, tem a capacidade de entrar no inseto por aberturas naturais, como boca, ânus e espiráculos.

Sendo assim, um dos locais possíveis de penetração do patógeno, seria via tegumento do tarso. Para isso, a aplicação da calda sobre a planta deve formar uma pequena camada de esporos, fazendo com que o inseto durante sua movimentação entre em contato com o inóculo. Este evento por depender da mobilidade do inseto é restrito a alguns momentos do ciclo de vida da cochonilha. As ninfas que saem do ovissaco procuram formar colônias em volta daquelas que a originaram e depois de introduzirem o rostro no substrato vegetal a $O$. praelonga só muda de local depois da ecdise (Lima, 1981). Os machos por sua vez, se movimentam mais, eles no segundo ínstar se locomovem em busca de locais mais protegidos, onde irão realizar a troca de pele.

Outro momento que pode haver movimentação da cochonilha na planta é em situações de super população. Este fato foi observado na colônia estoque mantida durante o estudo, onde a procura por espaço gerou uma intensa movimentação.

Esta possibilidade de ocorrer a adesão e penetração do patógeno via tarso promovida pela movimentação do inseto sobre folha, não ocorreu durante a realização dos bioensaios, uma vez que os insetos utilizados estavam em plena sucção de seiva. Esta alternativa pode eventualmente ocorrer em situações de campo, por meio da movimentação comportamental e em situações de elevada infestação.

Outra possibilidade de minimizar a ação da cera é a utilização de espalhante adesivo e/ou óleo mineral ou vegetal. O óleo vegetal emulsionável, além do efeito de espalhante adesivo, auxilia na penetração da calda em pequenos interstícios. Outro efeito proporcionado é o molhante, uma vez que estes produtos possuem afinidade com as ceras (Basf, 2003).

Neste trabalho foi utilizado espalhante adesivo (Tween $40^{\circledR}$ ) a $0,01 \%$ com objetivo de promover a mistura dos conídios com a água e de facilitar o contato da suspensão com o inseto. Em testes preliminares, utilizando-se óleo mineral a $1 \%$ sobre ninfas recém expelidas pela mãe, obteve-se resultados superiores a $80 \%$ de mortalidade, porém este efeito não se repetiu em bioensaios em que foram utilizados insetos de $2^{\circ}$ e $3^{\circ}$ ínstares. Foram feitos também testes do óleo mineral em associação com alguns isolados 
de fungos, inclusive o ESALQ-447, considerado isolado padrão. Não foi observada melhoria no desempenho das suspensões com óleo em relação àquelas preparadas somente com água e espalhante adesivo. Resultado semelhante foi obtido em experimentos realizados por Silva et al. (2003), onde obtiveram uma mortalidade de $66,3 \%$ com o uso isolado do fungo, este associado com óleo obteve-se mortalidade de $61,5 \%$ e óleo sozinho $54,9 \%$. Estes resultados sugerem que ainda há dúvidas em relação ao efeito potencializador do óleo. Desta forma, optou-se em utilizar nos testes de seleção suspensões preparadas com água e espalhante adesivo.

Existe também interação de patógenos com a camada de cera e lipídios da tectocutícula do hospedeiro. Esses elementos podem ter um efeito antibiótico sobre os patógenos, evitando por exemplo a penetração (Koidsumi, 1957 citado por Alves et al., 1998).

Outro fator que pode ter contribuído para a baixa eficácia dos isolados testados é a baixa densidade populacional usada nos bioensaios. Em altas densidades há disputa pelo alimento, que pode gerar no inseto um estresse de alimentação,e que muitas vezes aumenta a suscetibilidade do mesmo (Watanabe, 1987). Além disso, nessas condições podem ocorrer danos na camada de cera devido ao contato constante dos insetos, fato este que facilitaria a penetração do patógeno (Alves et at., 1998).

No caso de $O$. praelonga, além dos fatores já citados, a densidade populacional está diretamente relacionada com a quantidade de "honeydew" presente nas folhas e que servem de substrato para crescimento de patógenos saprofíticos. Alguns estudos sugerem que a presença de "honeydew" em grande quantidade nas folhas favoreçam o crescimento de inúmeras espécies de fungo, entre elas, Capnodium citri, Cladosporium oxysporum e C. gloeosporioides (Oliveira, 1996; Srivastava \& Thakre, 2000.

Existem algumas evidencias de que alguns fungos saprofíticos tem um papel importante na supressão de outros fungos saprofíticos por possuir uma maior habilidade de competição (Srivastava \& Thakre, 2000). Estes autores relatam que algumas espécies de Aspegillus, Monilia spp., e Trichoderma viride produzem metabólitos com atividade antibiótica. Esta capacidade apresentada por estes fungos pode estar atuando na inibição 
da ação dos conídios dos entomopatógenos aplicados nas folhas, reduzindo desta maneira a possibilidade do inseto ser infectado via tarso.

Para que seja possível a obtenção de novas espécies de fungos promissoras no combate a esta cochonilha é preciso dar continuidade a este programa de seleção, efetuando-se novos testes, com um número maior de isolados. Este trabalho representa o início dos estudos e foram utilizadas espécies nunca antes testadas, e os resultados obtidos são indícios iniciais do comportamento de alguns isolados, sendo que a conclusão definitiva do potencial de cada espécie só será obtida com a realização de maior número de bioensaios, inclusive testando novas espécies e isolados.

O fungo $C$. cladosporioides detectado na criação foi testado e, embora tenha ocorrido atacando um grande número de insetos da criação, o resultado de mortalidade obtido nos bioensaios foi de apenas 1,25\%. Este resultado, certamente está vinculado à baixa quantidade de "honeydew", devido a baixa densidade populacional. Esta espécie de fungo é normalmente saprofítica e pode ser encontrada sobre folhas de citros na presença de secreções açucaradas. A ação desse fungo é provavelmente promovida pelo crescimento do mesmo sobre as folhas e sobre o inseto, fazendo com que em algum momento o crescimento micelial seja generalizado. Esse fato faz com que o fungo colonize também a região anal, por onde o patógeno invade o inseto em direção da secreção açucarada, promovendo desta maneira danos mecânicos e morte do inseto. Este processo é lento, de tal maneira que mesmo tendo sido totalmente colonizado externamente pelo fungo, o inseto permanece moribundo e com movimentos lentos.

A ocorrência de epizootias de Cladosporium sp. em populações de afídeos é bastante relatada na literatura (Oliveira, 1996). Este fato motivou a realização de um estudo de patogenicidade realizado por Oliveira (1996). Em trabalhos realizados por este pesquisador, não foi repetido o sucesso observado no campo, ou seja, em laboratório este fungo não apresentou patogenicidade para Brevicoryne brassicae. Mediante este resultado, o pesquisador sugere que possa haver algum sinergismo entre Cladosporium sp.e outros inimigos naturais de B. brassicae. Além disso, a presença de grandes quantidades de "honeydew", como observada em elevadas populações de afídeos, possa favorecer o fungo. Os resultantes obtidos por esse autor são concordantes com os de 
Alves (2004) (Comunicação pessoal), quando testou esse fungo contra $O$. praelonga em condições de laboratório.

Apresentando um comportamento diferente das demais espécies testadas, os isolados de $V$. lecanii foram, em sua maioria, patogênicos à cochonilha, onde destacaram-se os isolados ESALQ-972 e ESALQ-1300 que proporcionaram mortalidades corrigidas de 46,6\% e 40,54\%, respectivamente, após 12 dias da aplicação. Este resultado já era esperado, uma vez que esta espécie é freqüentemente encontrada sobre pulgões e cochonilhas nas regiões tropicais e subtropicais, e no Brasil ocorre naturalmente sobre outras cochonilhas de citros (Alves et al., 1998). Além disso, o isolado ESALQ-1300 foi obtido de insetos infectados coletados na região de BebedouroSP sobre $O$. praelonga. Na ocasião, a epizootia do patógeno promoveu uma redução drástica na população deste inseto (H.S. Prates, 2001. Comunicação pessoal).

De acordo com Mier et al. (1991), V. lecanii pode provocar epizootias de grandes proporções em regiões de clima tropical, subtropical e temperado, em insetos das Ordens Hemiptera, Coleoptera e Diptera.

Os resultados obtidos com estes isolados são superiores aos resultados obtidos em laboratório por Viégas et al. (1995) com C. gloeosporioides, onde o isolado testado promoveu 41,35\% de mortalidade do inseto após 21 dias da aplicação. Esta espécie é considerada hoje como promissora no controle de $O$. praelonga, entretanto, o fato de haver isolados fitopatogênicos é um fator limitante que restringe muito o seu uso e exige um grande número de estudos que avaliem os riscos deste patógeno como agente de controle biológico. Segundo Sutton (1992) Colletotrichum é o gênero mais importante de fungos fitopatogênicos disseminado pelo mundo, especialmente em regiões sub-tropicais e tropicais. Este patógeno causa danos econômicos significantes em leguminosas, hortaliças, frutíferas, gramíneas e culturas perenes.

Em bioensaios visando comparar a patogenicidade de isolados de $C$. gloeosporioides obtidos de frutos de abacate, banana, pimentão, nêspera e vagem com isolados obtidos de adultos de $O$. praelonga, os autores concluíram que ambos são patogênicos para frutos injuriados artificialmente de banana, nêspera, abacate, vagem e pimentão causando-lhes apodrecimento nos ferimentos (Cesnik \& Bettiol, 1998). No 
mesmo trabalho, os autores testaram, em frutos de citros injuriados artificialmente, a fitopatogenicidade de 2 isolados de $C$. gloeosporioides, oriundos de flores com sintomas da podridão floral dos citros (PFC), utilizados como padrão de patogenicidade, e dois isolados de $C$. gloeosporioides (CTAA1 e CTAA2), agente de controle de $O$. praelonga. Pelos resultados obtidos os 4 isolados testados foram patogênicos para frutos de laranja Lima, Lima ácida Tahiti, Tangerina Cravo e Ponkan. Segundo os autores da pesquisa, estes resultados indicam que há necessidade de estudos complementares com frutos apresentando lesões de ocorrência natural.

Em trabalho semelhante realizado por Teixeira et al. (2001) foi constatado sintomas típicos de antracnose em frutos inoculados com C. gloeosporioides [CTAA(15)] isolados de $O$. praelonga. Em casa de vegetação a inoculação das flores com os fungos CTAA4, CTAA5 resultaram em lesões necróticas típicas da doença PFC.

Estes resultados reforçam a idéia de que há necessidade de se criar alternativas ao uso de $C$. gloeosporioides. Para isso, os resultados obtido neste trabalho são uma valorosa contribuição, pois foram selecionados dois isolados que apresentaram uma virulência superior em laboratório, e em testes iniciais em campo do isolado ESALQ-1300 foi observada uma redução drástica na população da cochonilha (H.S. Prates, 2003. Comunicação pessoal). Outra vantagem do $V$. lecanii em relação a $C$. gloeosporioides é o fato do mesmo não ser fitopatogênico. Além disso, já existe tecnologia de produção de formulações comerciais como o produto Vertalec ${ }^{\circledR} \mathrm{e}$ Mycotal $^{\circledR}$, que são comercializados pela Koppert (Holanda) e recomendados para o controle da mosca-branca e tripes (Koppert, 2004).

\subsection{Produção do isolado selecionado em diferentes sistemas de produção}

Por proporcionar uma mortalidade superior aos demais isolados, o material ESALQ-972 foi usado nesta etapa do trabalho, visando a avaliação de sua produção em diferentes sistemas de produção. Os resultados de produção obtidos encontram-se na Tabela 1. 
Tabela 1. Produção de conídios obtidas nos diferentes sistemas de produção (Piracicaba, 2003)

\begin{tabular}{cccc}
\hline Método & Conídios/grama & Viabilidade (\%) & Contaminantes \\
\hline Bandeja & $1.88 \times 10^{9} \mathrm{a}$ & 100 & ausentes \\
Caixa & $1.04 \times 10^{9} \mathrm{~b}$ & 100 & presentes \\
\hline
\end{tabular}

* médias seguidas de letras diferentes diferem entre si (Tukey 5\%)

A metodologia de produção proposta por Tanzini (2002), proporcionou um rendimento inferior de 80,7 \% em relação ao obtido pelo método das bandejas. Resultado semelhante foi obtido por Tanzini (2002), que em seus testes de avaliação de dois métodos de produção, concluiu que $V$. lecanii produziu $68 \%$ a mais no método da bandeja em relação ao da caixa.

Além do rendimento inferior, o uso da caixa apresentou diversas limitações de manipulação durante o processo de instalação.

Para que se tenha um produto isento de contaminantes é recomendado que a etapa de inoculação de arroz seja realizada dentro da câmara de fluxo laminar. Entretanto, devido às dimensões da caixa houve uma dificuldade do manuseio da mesma no momento da inoculação do arroz, instalação da bomba de ar e colocação da lâmina d'água. O comprometimento desta etapa aumenta os riscos de ocorrência de contaminantes durante o processo de produção.

Outro fator responsável pela ocorrência de contaminantes são as gotas de água formadas por condensação no interior da caixa que caem sobre o arroz e formam focos de contaminação (Tanzini, 2002).

Embora não quantificado, foi observada uma grande diferença de esporulação ao longo da camada de arroz, isto é, da superfície para as camadas internas ocorreu uma redução da esporulação, sendo esta restabelecida na camada superficial inferior. Este menor rendimento apresentado pela faixa interna de arroz é devido, provavelmente, a baixa oxigenação e menor incidência de luminosidade. Esta por sua vez é fundamental no processo de conidiogênese (Leite et al., 2003). Em camadas mais finas esta tendência é menos evidente, sugerindo que exista uma espessura de arroz ideal 
para a obtenção de um desempenho de produção homogenia ao longo do perfil da camada de arroz.

Apesar dos problemas, o sistema de produção em caixa representa alguns avanços em relação a produção pelo método das bandejas. Este elimina a etapa de incubação do patógeno em câmara climatizada. A injeção de ar forçado substituiu essa etapa, fornecendo a umidade necessária para o crescimento vegetativo do fungo e auxilia a secagem após a esporulação. Desta forma, há uma redução no tempo total de produção em aproximadamente cinco dias em relação ao método de bandeja (Tanzini, 2002).

O método da bandeja desenvolvido por Alves \& Pereira (1989) em colaboração com a Labormax Produtos Químicos Indústria e Comércio Ltda., proporcionou uma produção de 1.88 x $10^{9}$ conídios/grama de arroz. Além disso, o material obtido estava isento de contaminantes. Este método tem sido utilizado para produção de M. anisopliae, B. bassiana e de outros deuteromicetos (Alves et al., 1998).

Em teste preliminar visando o conhecimento da nova tecnologia de produção, foi usado o material ESALQ-1300, onde o mesmo apresentou uma baixa produção. Além disso, no preparo do inóculo deste material foi observado um baixo crescimento e conidiogênese na placa de Petri. Desta forma faz-se necessário uma adequação ou desenvolvimento de um novo sistema de produção para melhor aproveitamento deste isolado, uma vez que os fungos para serem utilizados no manejo microbiano de pragas na chamada estratégia inundativa, precisam estar disponíveis em grandes quantidades (Alves et al., 1998). Os resultados promissores obtidos em testes preliminares realizados em campo (Prates, 2003. Comunicação pessoal), reforçam a necessidade da obtenção de um método de produção eficiente, que seja capaz de fornecer quantidade suficiente do patógeno, visando a sua utilização como bioinseticida. Desta forma, estudos de novos métodos, substratos e o conhecimento das condições ideais de desenvolvimento do patógeno devem ser priorizadas.

Visando a obtenção de um novo substrato para produção de $V$. lecanii, Lopez \& Carbonell (1998) testaram mesocarpo de amêndoa e concluíram que, apesar de ter sido encontrado contaminação de diversos fungos saprófitos, este material pode ser uma nova alternativa. 
Em estudos biológicos e físicos de 8 isolados de $V$. lecanii, concluiu-se que a melhor temperatura de desenvolvimento desta espécie foi de $25^{\circ} \mathrm{C}$ e $\mathrm{pH} 7$ (Lopez \& Carbonell, 1999).

Espera-se que esses estudos contribuirão para que no futuro seja possível a obtenção de métodos que propiciem a produção em escala comercial de fungos entomopatogênicos, tornando o controle microbiano de pragas economicamente viável para ser utilizado em grandes áreas. 


\section{CONCLUSÕES}

- As espécies de Verticillium lecanii são patogênicas para Orthezia praelonga, sendo os isolados ESALQ-1300 e ESALQ-972 os mais promissores para utilização no controle desta praga.

- As espécies de Beauveria bassiana, B. brorgniartii, Cladosporium cladosporioides Paecilomyces fumosoroseus, P. lilacinus, Metarhizium anisopliae e Srorothrix sp. testadas nesta pesquisa não foram patogênicas ou apresentaram baixa virulência a Orthezia praelonga.

- O método da bandeja proporcionou um rendimento superior ao método da caixa na produção do isolado ESALQ-972. 
ANEXO 
Anexo A Plantas hospedeiras de Orthezia praelonga

\begin{tabular}{|c|c|c|}
\hline Espécies hospedeiras & Família & Nome vulgar \\
\hline Acalypha sp. & Euphorbiaceae & Acalypha \\
\hline Acalypha wilkesiana Muell. Arg. & Euphorbiaceae & Acalyfha \\
\hline Achras zapota (L.) Van Royen & Sapotaceae & sapoti, sapotizeiro \\
\hline Achyrantes sp. & Amaranthaceae & Achyrantes \\
\hline Aegiphila pernambucensis Moldenke & Verbenaceae & \\
\hline Ageratum conyzoides $\mathrm{L}$ & Compositae & Maria Preta, Mentrasto \\
\hline Alternanthera dentata (Moech) Scheygr & Amaranthaceae & \\
\hline Amarathus sp. & Amaranthaceae & Amarantos \\
\hline Anacardium occidentale L. & Anacardiaceae & Cajueiro \\
\hline Ananas sativos (L.) Merrill & Bromeliaceae & \\
\hline Annona muricata L. & Annonaceae & Graviola \\
\hline Anthurium andreanum Linden & Araceae & Antúrio \\
\hline Anthurium sp. & Araceae & Antúrio \\
\hline Artocarpus altilis (Parkinson) Fosberg & Moraceae & Fruta-Pão \\
\hline Artocarpus heterophyllus Lamarck & Moraceae & Jaca \\
\hline Baccharia sp. & Asteraceae & \\
\hline Bauhinia alba Vell. & Caesalpiniaceae & Pata de Vaca \\
\hline Bauhinia monandra Baill & Caesalpiniaceae & \\
\hline Bauhinia sp & Caesalpiniaceae & Pata de Vaca \\
\hline Besleria sp. & Gesneriaceae & \\
\hline Bidens pilosa $\mathrm{L}$. & Asteraceae & Picão Preto \\
\hline Bouganvillaea sp. & Nyctaginaceae & Bouganvillaea \\
\hline Bouganvillaea spectabilis Willd. & & Bouganvillaea \\
\hline Brachiaria purpuracens L. & Poaceae & Capim angola \\
\hline Breynia nivosa & Euphorbiaceae & Mil cores \\
\hline Brunfelsia sp. & Solanaceae & Manacá \\
\hline Byrsonima sericea D. C. & Malpighiaceae & Murici \\
\hline Cactus sp. & Cactaceae & Cactus \\
\hline
\end{tabular}


Anexo A Plantas hospedeiras de Orthezia praelonga

\begin{tabular}{|c|c|c|}
\hline Caesalpiniaceae peltophoroides Benth. & Caesalpiniaceae. & $\begin{array}{l}\text { Mucitaiba-Verdadeira, } \\
\text { Sibipiruna }\end{array}$ \\
\hline Cajanus indicus & Leguminosae & $\begin{array}{l}\text { Andu, Ervilha-de-angola, } \\
\text { Feijão-de-Árvore, Feijão- } \\
\text { Guandu, Guando }\end{array}$ \\
\hline Cajanus sp. & Leguminosae & Guandu \\
\hline Capsicum frutescens L. & Solanaceae & Pimenta Malagueta \\
\hline Capsicum $\mathrm{sp}$ & Solanaceae & Pimentão, Pimenta \\
\hline Carica papaya $\mathrm{L}$. & Caricaceae & Mamoeiro \\
\hline Carica sp. & Caricaceae & Mamoeiro \\
\hline Cassia sp. & Caesalpiniaceae. & Mata-pasto \\
\hline Cenchrua ecchinatus L. & Poaceae & \\
\hline Centrosema virginianum Benth & Leguminosae & $\begin{array}{l}\text { Feijao-do-Mato, Feijaozinho- } \\
\text { de-Capoeira; Jequiritirana }\end{array}$ \\
\hline Chrysanthemum morifolium ram. & Asteraceae & Crisântemo \\
\hline Citrus aurantium $\mathrm{L}$. & Rutaceae & Laranja Azeda \\
\hline Citrus latifolia Tanaka & Rutaceae & Lima ácida 'Tahiti' \\
\hline Citrus limetta Risso & Rutaceae & Lima \\
\hline Citrus limonia Osbeck & Rutaceae & Limão 'Cravo' \\
\hline Citrus reticulata Blanco & Rutaceae & 'PONKAN' \\
\hline Citrus sinensis Osbeck & Rutaceae & $\begin{array}{l}\text { Cultivares: Folha-Murcha, } \\
\text { Natal, Pêra, ponkan, Valência }\end{array}$ \\
\hline Citrus sp. & Rutaceae & Laranja \\
\hline Coccoloba sp. & Polygonaceae & $\begin{array}{l}\text { Cajoeiro Bravo, Cauacu, } \\
\text { Cauassu }\end{array}$ \\
\hline Coccoloba uvifera Salzm & Polygonaceae & \\
\hline Cocos nucifera L. & Palmae & Coco \\
\hline Codiaeum sp. & Euphorbiaceae & Croton \\
\hline Codiaeum variegatum Crantz & Euphorbiaceae & Croton, Louro-Variegado \\
\hline Coffea arabica $\mathrm{L}$. & Rubiaceae & Cafeeiro \\
\hline
\end{tabular}


Anexo A. Plantas hospedeiras de Orthezia praelonga

\begin{tabular}{|c|c|c|}
\hline Coffea sp. & Rubiaceae & Cafeeiro \\
\hline Coleus blumei Benth. & Labiatae & Coleus-de-Java \\
\hline Coleus sp. & Labiatae & Coleus \\
\hline Cordia corymbosa & Boraginaceae & \\
\hline Coreopsis grandiflora & Asteraceae & Camomila, Falsa-Camomila \\
\hline Croton sp. & Euphorbiaceae & Croton \\
\hline Cryptostegia madagascariensis Boj. & Asclepiadaceae & \\
\hline Cucurbita pepo L. & Cucurbitaceae & Abobrinha de moita \\
\hline Curcubita moschata Duchesne & Cucurbitaceae & Abóbora \\
\hline Dahlia sp. & Asteraceae & Dália \\
\hline Davalia surinamensia Cham. & Polypodiaceae & \\
\hline Dombeya acutangula Vog & Sterculiaceae & Aurora \\
\hline Dracaena sp. & Agavaceae & Dracena \\
\hline Eriobotrya japonica Lindl & Rosaceae & Nespereira \\
\hline Eugenia jambos L. & Myrtaceae & Jambo-Amarelo \\
\hline Eugenia uniflora $\mathrm{L}$. & Myrtaceae & Pitangueira \\
\hline Eupatorium sp & Asteraceae & Cambará-roxo, Mata Pasto \\
\hline Euphorbia sp. & Euphorbiaceae & Eufórbia \\
\hline Euphorbia thiracalli L. & Euphorbiaceae & Eufórbia \\
\hline Ficus canoni N. E. Br. & Moraceae & Ficus \\
\hline Gardenia florida L. & Rubiaceae & Gardenia \\
\hline Gardenia jasminoides Ellis & Rubiaceae & Gardenia \\
\hline Gossypium sp. & Malvaceae & Algodoeiro \\
\hline Graptophylum sp. & Acanthaceae & \\
\hline \multicolumn{3}{|l|}{ Haematoxylon sp. } \\
\hline Hedera helix L. & Araliaceae & Hera, Hédera, Hereira \\
\hline Hemigraphis colorata & Acanthaceae & Rubrastilis \\
\hline Hipiscus rosa sinensis L. & Malvaceae & $\begin{array}{l}\text { Hibisco(amarelo, beje,rosa,dobr } \\
\text { ado,vermelho) }\end{array}$ \\
\hline Hipiscus syriacus $\mathrm{L}$. & Malvaceae & Hibisco \\
\hline
\end{tabular}


Anexo A. Plantas hospedeiras de Orthezia praelonga

\begin{tabular}{|c|c|c|}
\hline Hipiscus tiliaceus L. & Malvaceae & Hibisco \\
\hline Hyptis sp. & Labiatae & $\begin{array}{l}\text { Alfavaca-De-Caboclo, } \\
\text { Bambural; Bamburral, } \\
\text { Manjeiricão, Sambacuite; } \\
\text { Sambaite }\end{array}$ \\
\hline Indigofera hirsuta $\mathrm{L}$. & Leguminosae & Mata-pasto-preto \\
\hline Ipomoea fistulosa $\mathrm{L}$. & Convolvulaceae & $\begin{array}{l}\text { Algodão bravo, Majorana, } \\
\text { Canudo, Mata-Cabra }\end{array}$ \\
\hline Ixora coccinea $\mathrm{L}$. & Rubiaceae & Ixora \\
\hline Lantana $\mathrm{sp}$ & Verbenaceae & Lantana \\
\hline Lawsonia inermis L. & Lythraceae & Henna \\
\hline Leonotis nepaentifolia $\mathrm{L}$. & Labiatae & \\
\hline Lonicera sp. & Caprifoliaceae & Enredadeira, Madreselva \\
\hline Loranthus sp. & Loranthaceae & \\
\hline \multicolumn{3}{|l|}{ Macrotilium sp } \\
\hline Malpighia glabra & Malpighiaceae & Acerola \\
\hline Malpighia sp. & Malpighiaceae & Acerola \\
\hline $\begin{array}{l}\text { Malvastrum coromandelianum (L.) } \\
\text { Garcke }\end{array}$ & Malvaceae & $\begin{array}{l}\text { Guanxuma, Vassourinha, } \\
\text { Guaxima, Malvastro }\end{array}$ \\
\hline Malvastrum sp. & Malvaceae & \\
\hline Malvicus sp. & Malvaceae & \\
\hline Mangifera indica $\mathrm{L}$. & Anacardiaceae & Manga \\
\hline Mangifera sp. & Anacardiaceae & Manga \\
\hline Manihot esculenta Crantz & Euphorbiaceae & $\begin{array}{l}\text { Aipim, Macaxeira, Mandioca, } \\
\text { Maniva }\end{array}$ \\
\hline Mentha piperita $\mathrm{L}$. & Labiatae & Hortelã, Hortelã-Pimenta \\
\hline Mirabilis jalapa $\mathrm{L}$. & Nictaginaceae & Bonina, Maravilha \\
\hline Mormodica charantia & Cucurbitaceae & Melão-de-São-Caetano \\
\hline Panicum plantagineum L. & Poaceae & Capim \\
\hline Panicum sp. & Poaceae & Capim \\
\hline
\end{tabular}


Anexo A. Plantas hospedeiras de Orthezia praelonga

\begin{tabular}{|c|c|c|}
\hline Parderia sp. & Rubiaceae & \\
\hline Passiflora edulis Sims & Passifloraceae & Maracujá \\
\hline Passiflora quadrangularis $\mathrm{L}$. & Passifloraceae & Maracujá-Açú \\
\hline Pentas sp. & Rubiaceae & \\
\hline Peristrophe angustifolia Nees & Acanthaceae & Pingo de Ouro \\
\hline Phylanthus corcovadensis Muell. Arg. & Euphorbiaceae & Quebra-Pedra \\
\hline Phylanthus distinchus Muell. Arg. & Euphorbiaceae & \\
\hline Phylanthus sp. & Euphorbiaceae & \\
\hline Phylodendron sp. & Araceae & Cipó-Imbé \\
\hline Pimpinella anisum L. & Umbeliferae & Anis, Erva-Doce \\
\hline Piper marginatum & Piperaceae & Pimenta do Mato \\
\hline Piper nigrum & Piperaceae & Pimenta do Reino \\
\hline Piper sp. & Piperaceae & Pimenta \\
\hline Pisonia sp. & Nictaginaceae & Piranha \\
\hline Plumbago caerulea H.B. \& K. & Plumbaginaceae & \\
\hline Plumeria alba L. & Apocynaceae & Jasmim de Caiena \\
\hline Plumeria rubra $\mathrm{L}$. & Apocynaceae & $\begin{array}{l}\text { Jasmim de Caiena Jasmim de } \\
\text { São José, Jasmim do Pará, } \\
\text { Jasmim Manga }\end{array}$ \\
\hline Polypodium vacciniifolium Langsd. \& Fis & Polypodiaceae & \\
\hline Portulaca sp. & Portulaceae & Onze-Horas \\
\hline $\begin{array}{l}\text { Pseuderanthemum atropurpureum } \\
\text { (Bull)Bailey }\end{array}$ & Acanthaceae & \\
\hline Psidium araça Raddi & Myrtaceae & $\begin{array}{l}\text { Araca, Araçazeiro, Araçá- } \\
\text { Verdadeiro }\end{array}$ \\
\hline Psidium guayava $\mathrm{L}$. & Myrtaceae & Goiabeira \\
\hline Psidium sp. & Myrtaceae & Goiabeira \\
\hline Pterocarpus violaceus Vog. & Papilionoideae & Pau-sangue \\
\hline Rosa sp. & Rosaceae & Rosa \\
\hline Saccharum sp. & Poaceae & Cana de açúcar \\
\hline
\end{tabular}


Anexo A. Plantas hospedeiras de Orthezia praelonga

\begin{tabular}{|c|c|c|}
\hline Sanchezia nobilis & Acanthaceae & Sanchezia \\
\hline Sanchezia sp. & Acanthaceae & Sanchezia \\
\hline Sapium sp. & Euphorbiaceae & \\
\hline Schefflera arboricola & Araliaceae & Folhagem Schefflera \\
\hline Sida rhombifolia $\mathrm{L}$. & Malvaceae & Guaxuma, Malva Preta \\
\hline Sida sp. & Malvaceae & \\
\hline Sida urens $\mathrm{L}$. & Malvaceae & $\begin{array}{l}\text { Guanxuma-Dourada, Guanxuma- } \\
\text { Rasteira }\end{array}$ \\
\hline Solanum asperum L. C. Richard & Solanaceae & \\
\hline Phylanthus sp. & Euphorbiaceae & \\
\hline Phylodendron sp. & Araceae & Cipó-Imbé \\
\hline Pimpinella anisum $\mathrm{L}$. & Umbeliferae & Anis, Erva-Doce \\
\hline Piper marginatum & Piperaceae & Pimenta do Mato \\
\hline Piper nigrum & Piperaceae & Pimenta do Reino \\
\hline Piper sp. & Piperaceae & Pimenta \\
\hline Pisonia sp. & Nictaginaceae & Piranha \\
\hline Plumbago caerulea H.B. \& K. & Plumbaginaceae & \\
\hline Plumeria alba $\mathrm{L}$. & Apocynaceae & Jasmim de Caiena \\
\hline Plumeria rubra $\mathrm{L}$. & Apocynaceae & $\begin{array}{l}\text { Jasmim de Caiena Jasmim de } \\
\text { São José, Jasmim do Pará, } \\
\text { Jasmim Manga }\end{array}$ \\
\hline Polypodium vacciniifolium Langsd. \& Fis & Polypodiaceae & \\
\hline Portulaca sp. & Portulaceae & Onze-Horas \\
\hline $\begin{array}{l}\text { Pseuderanthemum atropurpureum } \\
\text { (Bull)Bailey }\end{array}$ & Acanthaceae & \\
\hline Psidium araça Raddi & Myrtaceae & $\begin{array}{l}\text { Araca, Araçazeiro, Araçá- } \\
\text { Verdadeiro }\end{array}$ \\
\hline Psidium guayava $\mathrm{L}$. & Myrtaceae & Goiabeira \\
\hline \begin{tabular}{|l} 
Psidium sp. \\
\end{tabular} & Myrtaceae & \begin{tabular}{|l} 
Goiabeira \\
\end{tabular} \\
\hline \begin{tabular}{|l} 
Pterocarpus violaceus Vog. \\
\end{tabular} & Papilionoideae & \begin{tabular}{|l} 
Pau-sangue \\
\end{tabular} \\
\hline
\end{tabular}


Anexo A. Plantas hospedeiras de Orthezia praelonga

\begin{tabular}{|c|c|c|}
\hline Rosa sp. & Rosaceae & Rosa \\
\hline Sanchezia nobilis & Acanthaceae & Sanchezia \\
\hline Saccharum sp. & Poaceae & Cana de açúcar \\
\hline Sanchezia sp. & Acanthaceae & Sanchezia \\
\hline Sapium sp. & Euphorbiaceae & \\
\hline Schefflera arboricola & Araliaceae & Folhagem Schefflera \\
\hline Sida rhombifolia $\mathrm{L}$. & Malvaceae & Guaxuma, Malva Preta \\
\hline Sida sp. & Malvaceae & \\
\hline Sida urens L. & Malvaceae & $\begin{array}{l}\text { Guanxuma-Dourada, Guanxuma- } \\
\text { Rasteira }\end{array}$ \\
\hline Solanum asperum L. C. Richard & Solanaceae & \\
\hline Solanum balbissi Dum & Solanaceae & \\
\hline Solanum tuberosum $\mathrm{L}$. & Solanaceae & Babata \\
\hline Spathodea campanulata Veauv & Bignoniaceae & $\begin{array}{l}\text { Árvore-da-Bisnaga, Árvore-de- } \\
\text { Tulipa, Campanula-Vermelha, } \\
\text { Tulipa-Africana, Tulipeira }\end{array}$ \\
\hline Talisia esculenta Radlh & Sapindaceae & Pitomba, Pitombeira \\
\hline Tecoma apeciosa D.C & Bignoniaceae & \\
\hline Terminalia catappa $\mathrm{L}$. & Combretaceae & $\begin{array}{l}\text { Amendoeira, Chapeu-de-sol, } \\
\text { Sete-Copas }\end{array}$ \\
\hline Thunbergia sp. & Acanthaceae & Tumbergia \\
\hline Thunpergia speciosa Boj & Acanthaceae & Tumbergia \\
\hline Tillandsia aeranthos & Bromeliaceae & Cravo do Mato \\
\hline Triplaris filipensis Cham & Polygonaceae & \\
\hline Triplaris sp. & Polygonaceae & Vara de Maria \\
\hline Triplaris surinamensis Cham. & Polygonaceae & Vara de Maria \\
\hline Triumfetta semitriloba Jacq. & Tiliaceae & \\
\hline Vernomia cinerea Less & Asteraceae & \\
\hline Vernonia sp. & Asteraceae & Assa-peixe \\
\hline
\end{tabular}


Anexo A. Plantas hospedeiras de Orthezia praelonga

\begin{tabular}{|l|l|l|}
\hline Vernonia squamulosa Less. & Asteraceae & \\
\hline Viola sp. & Violaceae & Amor perfeito \\
\hline Wedelia paludosa D.C & Asteraceae & Malmequer \\
\hline Wedelia sp. & Asteraceae & Vedélia \\
\hline
\end{tabular}




\section{REFERÊNCIAS BIBLIOGRÁFICAS}

ABBOTT, W.S. A method of computing the effectiveness of an insecticide. Journal of Economic Entomology, v.18, p.265-267, 1925.

ALMEIDA, J.E.M.; ALVES, S.B.; PEREIRA, R.M. Selection of Beauveria spp. isolates for control of the termite Heterotermes tenuis (Hagen, 1858). Journal of Applied Entomology, v.121, p.539-543, 1997.

ALVES, S.B. (Coord.) Controle microbiano de insetos. 2. ed. Piracicaba: FEALQ, 1998. 1163p.

ALVES, S.B.; PEREIRA, R.M.P. Produção de Metarhizium anisopliae (Metsch.) Sorok. e Beauveria bassiana (Bals.) Vuill. em bandejas. Ecossistema, v. 14, p.188-192, 1989.

ALVES, S.B.; ALVES, L.F.A.; LOPES, R.B.; VIEIRA, S.A. Isolado 1037 de Metarhizium anisopliae promissor para o controle microbiano de insetos. In: CONGRESSO BRASILEIRO DE ENTOMOLOGIA, 16., ENCONTRO NACIONAL DE FITOSSANITARISTAS, 7., Salvador, 1997. Anais. Salvador:Sociedade Entomológica do Brasil, 1997. p.139.

ALVES, S.B.; MEDEIROS, M.B.; TAMAI, M.A; LOPES, R.B. Trofobiose e microrganismos na proteção de plantas. Biotecnologia Ciência \& Desenvolvimento, n.21, p.16-21, jul./ago. 2001. 
BASF. Catálogo de produtos fitosanitario, Brasil, 2003. http://www.basf.com.br/cat_eletronico/it_adj_prep.htm (17 dez. 2003).

BOBADILLA, D.; VARGAS, H.; JIMÉNES, P. G.; SEPÚLVEDA, G.; MENDOZA, R. Enemigos naturales de las conchuelas móviles, Orthezia spp. (Homoptera: Ortheziidae), detectados en el Norte de Chile. Idesia, v.16, p.117-123, 1999.

BUCKNER, J.S.; HAGEN, M.M.; NELSON, D.R. The composition of the cuticular lipids from nymphs and exuviae of the silverleaf whitefly Bemisia argentifolii. Journal Comparative Biochemistry and Physiology. B. Biochemistry \& Molecular Biology, v.124, p.201-207, 1999.

CARVALHO, R.S.; NASCIMENTO, A.S.; SANCHES, N.F. Controle da Orthezia dos citros. Cruz das Almas: Embrapa, CPNF, 1998. 15p. (Embrapa. CPNF. Circular Técnica, 31).

CARVALHO, V.A.M. Avaliação de fungos e nematóides entomopatogênicos e sua compatibilidade com produtos fitossanitários visando o controle da cochonilha-daraiz-do-cafeeiro, Dysmicoccus texensis Tinsley (Hemiptera-Pseudococcidae). Lavras, 2003. 82p. Dissertação (Mestrado) - Universidade Federal de Lavras.

CASSINO, P.C.R.; LIMA, A.F.de RACCA FILHO, F. Orthezia praelonga Douglas, 1891 em plantas cítricas no Brasil (Homoptera, Ortheziidae). Arquivos da Universidade Federal do Rio de Janeiro, v.14, n.1, p.27-34, 1991.

CASSINO, P.C.R.; PERRUSO, J.C.; NASCIMENTO, F.N. do. Contribuição dos conhecimentos das interações biecológicas entre Aleirodideos (Homoptera, Aleyrodidae) e Orthezia praelonga Douglas, 1891 (Homoptera, Ortheziidae) no agroecossistema cítrico. Anais da Sociedade Entomológica do Brasil, v.22, n.1, p.209-212, 1993. 
CASSINO, P.C.R.; COSTA, F.A.; DALCOMO, E.L.; ROCCA FILHO, F. Contribuição para o controle integrado da Orthezia praelonga, Douglas 1891 (homoptera, Ortheziidae) em Citus spp. A Lavoura, v.78, p.5-8, 1975.

CESNIK, R.; BETTIOL, W. Potencial fitopatogênico de Colletotrichum gloeosporioides, agente de controle biológico de Orthezia praelonga (Homoptera, Ortheziidae). Laranja, v.19, n.2, p.261-268, 1998.

CESNIK, R.; FERRAZ, J.M.G.; OLIVEIRA, R.C.A.L.; ARELLANO, F.; MAIA, A.H.N. Controle de Orthezia praelonga com o fungo Colletotrichum gloeosporioides isolado orthezia, na região de Limeira, SP. In: SIMPÓSIO DE CONTROLE BIOLÓGICO, 5., Foz de Iguaçu, 1996. Anais. Curitiba: Eventos,1996. p.363.

CHIAVEGATO, L.G. Ácaros da cultura de citros. In: RODRIGUEZ, O.; VIÉGAS, F.; POMPEU Jr., J.; AMARO, A.S. (Ed). Citricultura brasileira. 2.ed. Campinas: Fundação Cargill, 1991. v.2, p.601-641.

COORDENADORIA DE ASSISTÊNCIA TÉCNICA INTEGRAL. Recomendações para o controle das principais pragas e doenças em pomares do Estado de São Paulo. 5. ed. Campinas, 1997. 58p (Boletim Técnico, 165).

COSTA LIMA, A.M. Homópteros. In: COSTA LIMA, A. M. Insetos do Brasil. Rio de Janeiro: E.N.A., 1942. v.3, 327p.

CRUZ, J.D.; MARQUES, O.M.; NASCIMENTO, A.S. Consumo de Orthezia praelonga Douglas, 1891 (Insecta: Ortheziidae) por Oxystyla pulchella spix, 1827 (Gastropoda: Bulimullidae) em laboratório. Sitientibus. n.20, p.81-88, 1999. 
DE NEGRI, J.D. O controle de Orthezia em citros. Campinas: CATI, 1983. 3p. (Comunicado Técnico, n 45).

FENG, M.; JOHNSON, J.B. Relative virulence of six isolates of Beauveria bassiana on Diuraphis nixia (Homoptera: Aphididae). Environmental Entomology, v.19, n.3, p.785-790, 1990.

FRIGO, S.M.; AZEVEDO, J.L. Variabilidade natural para crescimento, conidiação e sobrevivência à luz ultra-violeta em Metarhizium anisopliae (Metsch.) Sorokin. Revista de Agricultura, v.61, n.2, p.137-147, 1986.

GALlO, D.; NAKANO, O.; SILVEIRA NETO, S.; CARVALHO, R.P.L.; BATISTA, G.C.; BERTI FILHO, E.; PARRA, J.R.P.; ZUCCHI, A.R.; ALVES, S.B.; VENDRAMIN. J.D. Manual de entomologia agrícola. São Paulo:FEALQ, 2002. 920 .

GARCIA, M.O.; SINISGALLI, D.L.; ALVES, S.B.; TAMAI, M.A.; LOPES, R.B.. Seleção de isolados de fungos entomopatogênicos para o controle de Orthezia praelonga (STERNORRYNCHA:ORTHEZIIDAE). In: SIMPÓSIO INTERNACIONAL DE INICIAÇÃO CIENTÍFICA DA USP, 8., São Paulo, 2000. Anais. Piracicaba: ESALQ, 2000. p.23.

GOMES, J.G.A. A "fumagina" e o piolho "Orthezia" da laranjeira e do limoeiro. Seleção Agrícolas, v.9, n.104, p.21-22, 1954.

GONÇALVES. C.R. Procedimento da Orthezia na Baixada Fluminense e o seu combate racional. Boletim de Campo, v.19, n.166, p.12-16, 1963. 
GONÇALVES. C.R.; CASSIANO, P.C.R. O problema da Orthezia praelonga na citricultura. In: ENCONTRO NACIONAL DE CITRICULTURA, 5., Rio de Janeiro , 1978. Anais. Rio de Janeiro: Pesagro, 1978. p.5.

GRAVENA, S. Manejo integrado de pragas dos citros no Brasil. In: RODRIGUES, A.; VIÉGAS, F.; POMPEU, J.; AMARO, A.S (Ed.). Citricultura brasileira. 2.ed. Campinas: Fundação Cargill, 1991. v.2. p.852-868.

GRAVENA, S. Manual prático de inspeção de pragas em citros. Jaboticabal: GRAVENA-ManEcol., 2002. 54 p.

GUIRADO, N.; SAKAI, E.; AMBROSANO, E.J. Avaliação de efeito do óleo de nim extraído de sementes de Azadirachta indica no controle da cochonilha Ortézia em laranja Pêra. Revista de Agricultura, v.76, n.3, p.401-409, 2001.

JACKSON, C.W.; HEALE, J.B.; HALL, R.A. Traits associated with virulence to the aphid Macrosiphoniella sanborni in eightteen isolates of Verticillium lecanii. Annals of Applied Biology, v.106, p.39-48, 1985.

KOOPERT. Pest control: pest control products. http://www.koppert.nl/e002.shtml (04 Fev. 2004)

LECUONA, R.E.; TIGANO, M.S.; DIAZ, B.M. Characterization and pathogenicity of Beauveria bassiana against Diatraea saccharalis (F.) (Lepidoptera: Pyralidae) in Argentina. Anais da Sociedade Entomológica, v.25, n.2, p.299-307, 1996.

LEITE, L.G.; BATISTA FILHO, A.; ALMEIDA, J.E.M.; ALVES, S.B. Produção de fungos entomopatogênicos. Ribeirão Preto: A.S. Pinto, 2003. 92 p. 
LIMA, A.F. Biecologia de Orthezia praelonga Douglas, 1981 (Homoptera, Ortheziidae). Piracicaba, 1981. 126p. Dissertação (Mestrado) - Escola Superior de Agricultura "Luiz de Queiroz", Universidade de São Paulo.

LIMA, A.F.; CASSINO, P.C.R.; RODRIQUES FILHO, I.L.. Considerações sobre propagação e disseminação de Orthezia praelonga Douglas, 1891 (HomopteraOrtheziidae), em pomares cítricos no Estado do Rio de Janeiro. In: CONGRESSO BRASILEIRO DE ENTOMOLOGIA, 6., Campinas, 1980. Resumos. Campinas: Fundação Cargill, 1980. p.311.

LOPES, R.B. Seleção de entomopatógenos e controle de Frankliniella occidentalis (Thysanoptera: Thripidae). Piracicaba, 1999. 72p. Dissertação (Mestrado) - Escola Superior de Agricultura “Luiz de Queiroz”, Universidade de São Paulo.

LOPEZ, L.L.V.; CARBONELL, T. Use of almond mesocarp for production of the entomopathogenic fungus Verticillium lecanii. Canadian Journal of Microbiology, v.44, n.9, p-886-895, 1998.

LOPEZ, L.L.V.; CARBONELL, T. Characterization of spanish strains of Verticillium lecanii. Revista Iberoamericana, v.16, n.3, p-136-142, 1999.

LOURENÇÃO, A.L.; MIRANDA, M.A.; ALVES, S.B. Ocorrência epizoótica de Verticillium lecanii em Bemisia tabaci biótipo B (Hemiptera: Aleyrodidae) no Estado do Maranhão. Neotropical Entomology, v.30, n.1, p.183-185, 2001.

MANIANIA, N.K.; FARGUES, J. Susceptibility of Mamestra brassicae (L.), and Spodoptera littoralis (Boisd.) larvae (Lep., Noctuidae) to the hyphomycetes Paecilomyces fumosoroseus (Brown and Smith) and Nomuraea rileyi (Samson) at two temperatures. Journal of Applied Entomology, v.113, n.5, p.518-524, 1992. 
MANZINI, A.R.C.; ALVES, S.B.; LOPES, R.B.; ALVES, L.F.A. Seleção de isolados e estratégia de aplicação de fungos entomopatogênicos para o controle de Blatella germanica. In: SIMPÓSIO DE INICIAÇÃO CIENTÍFICA DA UNIVERSIDADE DE SÃO PAULO, 6., Piracicaba, 1998. Resumos. Piracicaba: USP, 1998. p.503.

MIER, T.; RIVERA, BERMÚDEZ, J.; DOMÍNGUEZ, Y.; BENAVIDES, C.; ULLÓA, M. Primer reporte en México del aislamiento de Verticillium lecanii a partir de la mosquita branca y pruebas de patogenecidad in vitro sobre este insecto. Revista Mexicana de Micología, v.7, p.49-165, 1991.

MOINO JÚNIOR, A. Utilização de Metarhizium anisopliae (Metsch.) Sorok. e Beauveria bassiana (Bals.) Vuill. para o controle de pragas de grãos armazenados. Piracicaba, 1993. 100p. Dissertação (Mestrado) - Escola Superior de Agricultura "Luiz de Queiroz", Universidade de São Paulo.

MOORHOUSE, E.R.; GILLESPIE, A.T.; CHARNLEY, A.K. Laboratory selection of. Metarhizium spp. isolates for control of vine weevil larvae (Otiorhynchus sulcatus). Journal of Invertebrate Pathology, v.62, n.1, p.15-21, 1993 a.

MOORHOUSE, E.R.; GILLESPIE, A.T.; CHARNLEY, A.K. Selection of. virulent and persistent Metarhizium anisopliae isolates to control black vine weevil (Otiorhynchus sulcatus.) larvae on glasshouse begonia. Journal of Invertebrate Pathology, v.62, n.1, p47-52, 1993 b.

NAKANO, O. Insetos nocivos aos citros. In: RODRIGUES, A.; VIÉGAS, F.; POMPEU, J.; AMARO, A.S (Ed.). Citricultura brasileira. 2.ed. Campinas: Fundação Cargill, 1991, 2v, p 557-574. 
NASCIMENTO, A.S. do. Ecologia da Orthezia praelonga. DOUGLAS, 1981 (Homoptera: Ortheziidae) na região de Cruz das Almas-BA. Cruz das Almas: Embrapa, CNPMF, 1980. 4p. (Comunicado técnico)

NASCIMENTO, A.S. do; MAGALHÂES, A.F.J.; SANCHES, N.F. O caracol rajado traz benefícios para o pomar cítrico. Cruz das Almas:BA: Embrapa, Cnpmf, 1993. 2p. (Embrapa/Cnpmf, Citros em Foco, 106).

NASCIMENTO, F.N. do; PERRUSO, J.C, CASSINO, P.C.R. Novos hospedeiros de Orthezia praelonga, Douglas 1891 (homoptera, Ortheziidae). Anais da Sociedade Entomopatológica do Brasil, v.22, n.1 p.213-215, 1993.

NEVES, E.M.; DAYOUB, M.; DRAGONE, D.S; NEVES, M.F. Citricultura brasileira: Efeitos econômicos-financeiros, 1996-2000. Revista Brasileira de Fruticultura, v.23, n.2, p.432-436, ago. 2001.

NEVES, E.M.; RODRIGUES, L.; DAYOUB, M.; DRAGONE, D.S. Citricultura: geração de divisas no plano real. Bebedouro: Coopercitrus, 2003, p.16 (Coopercitrus Informativo Agropecuário, 2003)

OLIVEIRA, E. Interação entomopatogênica de Cladosporium sp A Brevicoryne brassicae Linnaeus, 1978 (Homoptera: Aphididae) Em Couve (Brassica oleracea) na região de Lavras-MG. Lavras, 1996. 44p. Dissertação (Mestrado) - Universidade Federal de Lavras.

PARRA, J.R.P.; OLIVEIRA, H.N.; PINTO, A.S. Guia ilustrado de pragas e insetos benéficos dos citros. Piracicaba: A. S. Pinto, 2003. 140p 
PARRA, J.R.P.; BOTELHO, P.S.M.;CORRÊA-FERREIRA, B.S.; BENTO, J.M.S. (Ed). Controle biológico no Brasil: parasitóides e predadores. São Paulo: Ed. Manole. 2002. 635p.

PRATES, H.S. Ortézia, uma praga especial. Casa da Agricultura, v.9, p.16-19,1987.

PRATES, H.S. Piolho branco, a praga dos citros. Agroquímica Ciba- Geigy, n.12, p. 11-13, 1980.

PRATES, H.S.; PINTO, W.B.S. Orthezia praelonga Douglas, 1891: uma praga em potencial na citricultura. Campinas: CATI, 1986. 4p. (Comunicado técnico)

PUZZI, D.; CAMARGO, A.P. Estudo sobre a possibilidade de adaptação climática da Orthezia praelonga Douglas, nos pomares de citros do Estado de São Paulo. O Biológico, v.29, n.5, p.81-85, 1963.

ROBBS, C.F. O "piolho branco" da laranjeira, uma ameaça a citricultura do Distrito Federal. Boletim do Campo, v.3, n.1, p.1-4, 1947.

ROBBS, C.F. Enfermidades e pragas nos Estados da Guanabara e do Rio de Janeiro. A Lavoura, v.76, n.9, p.21-28, 1973.

ROBBS, C.F.; BITTENCOURT, A.M. Controle biológico de insetos: O controle Biológico de insetos nocivos à agricultura com o emprego de fungos imperfeitos ou hifomicetos. Biotecnologia Ciência \& Desenvolvimento, n.6, p.10-12, jul./ago. 1998.

ROBBS, C.F.; CESNIK, R.; SADI, C.V.S.; SÁ, L.A.N.; LUCHINI, F. Controle da Orthezia praelonga. In: CONGRESSO BRASILEIRO DE ENTOMOLOGIA, 14., Piracicaba, 1993. Resumos. Piracicaba: SEB, 1993. p.305. 
ROSAMIGLIA, A.C. Caracterização morfológica e bioquímica de Colletotrichum gloesoporioides (PENZ.) PENZ. \& SACC; Agente de controle da Orthezia praelonga Douglas, 1891. Rio Claro, 1998. 100p. Dissertação (Mestrado) - Instituto de Ciências Biológicas, Universidade Estadual Paulista "Julio de Mesquita Filho".

ROSAMIGLIA, A.C.; MELO, I.S. Caracterização morfológica e bioquímica de Colletotrichum gloeosporioides, agente de controle biológico de Orthezia praelonga. In: SIMPÓSIO DE CONTROLE BIOLÓGICO, 5., Foz de Iguaçu, 1996. Anais. Foz do Iguaçu: Embrapa, 1996. p.399.

SANCHES, N.F.; CARVALHO, R.S.; SILVA, E.S.; SANTOS FILHO, H.P. Eficiência do fungo entomopatogênico Cladosporium cladosporioides sobre Orthezia praelonga (Hemiptera: Orheziidae) em citrus na região do recôncavo baiano. In: SIMPÓSIO DE CONTROLE BIOLÓGICO, 8., São Pedro, 2003. Anais. São Pedro: Sociedade Entomológica do Brasil, 2003. p.97.

SILVA, E.S.; SANCHES, N.F.; SANTOS FILHO, H.P. Avaliação do fungo entomopatogênico Cladosporium cladosporioides associado a inseticidas no controle biológico de Orthezia praelonga (Hemiptera: Ortheziidae). In: SIMPÓSIO DE CONTROLE BIOLÓGICO, 8, São Pedro, 2003. Anais. São Pedro: Sociedade Entomológica do Brasil, 2003. p.100.

SUPLICY FILHO, N.; SAMPAIO, A. S.; MYAZAKI, I. Considerações sobre o coccídeo Orthezia praelonga Douglas, 1981, Importante praga da citricultura brasileira. O Biológico, v.49, n.1, p.19-24, 1983.

SUTTON, B.C. The genus Glomerella and its anamorph Colletotrichum In: BAILEY, J.A., JEGER, M.J. Colletotrichum: biology, pathology and control. Wallingford: CAB International, 1992. c.1, p.1-26. 
SRIVASTAVA, V.K.; THAKRE, R.P. Synergism and antagonism among the fungi grown in honeydew secretion on leaf surface of Nagpur mandarin. Indian Phytopathology, v.53, n.2, p.193-196, 2000.

TAMAI, M.A. Avaliação de fungos entomopatogênicos para o controle de Tetranychus urticae Koch. Piracicaba, 1997. 86p. Dissertação (Mestrado) - Escola Superior de Agricultura "Luiz de Queiroz", Universidade de São Paulo.

TAMAI, M.A; LOPES, R.B.; ALVES, S.B. Manejo de pragas na floricultuta. In: REUNIÃO ITINERANTE DE FITOSSANIDADE DO INSTITUTO BIOLÓGICO. Mogi das Cruzes, 2000. Anais. Mogi das Cruzes: Instituto Biológico, 2000. p.7782.

TANZINI, M.R. Controle do percevejo de renda da seringueira (Leptopharsa heveae) com fungos entomopatogênicos. Piracicaba, 2002. 140p. Tese (Doutorado) - Escola Superior de Agricultura “Luiz de Queiroz”, Universidade de São Paulo.

TEIXEIRA, M.A.; BETTIOL, W.; CESNIK, R. Patogenicidade do fungo Colletotrichum gloeosporioides, patógeno de Orthezia praelonga, para folhas, frutos e flores cítricas. Summa Phytopathologica, v.27, n.4, p.352-357, 2001.

VASCONCELlOS, H. O.; CRUZ, C. A.; OLIVEIRA, A. M. Avaliação da capacidade de reprodução de Orthezia praelonga Douglas, 1891, em ambiente de laboratório e insetário. Anais da Sociedade Entomológica do Brasil, v. 9, n.2, p. 189-197, 1980.

VENDRAMIM, J.D. O controle biológico e a resistência de plantas. In: PARRA, J.R.P.; BOTELHO, P.S.M.;CORRÊA-FERREIRA, B.S.; BENTO, J.M.S. (Ed). Controle biológico no Brasil: parasitóides e predadores. São Paulo: Ed. Manole, 2002. p.511-528. 
VIEGAS, E.C.; SAMPAIO, H.N.; CARVALHO, P.O.L. PERRUSO, J.C.; CASSINO, P.C.R. Controle alternativo de Orthezia praelonga Douglas, 1891 (Homoptera, Ortheziidae) em laboratório. In: CONGRESSO BRASILEIRO DE ENTOMOLOGIA, 15., Caxambú, 1995. Anais. Caxambu: Sociedade Entomológica do Brasil, 1995. p.333.

VIEIRA, S.A.; ALVES, S.B.; STIMAC, J.L.; ESTAVAM, R.C. Seleção de isolados de Metarhizium anisopliae e Beauveria bassiana para o controle de Periplaneta americana (L.). In: CONGRESSO BRASILEIRO DE ENTOMOLOGIA, 14., ENCONTRO NACIONAL DE FITOSSANITARISTAS, 5., Piracicaba, 1993. Anais. Piracicaba: FEALQ. 1993. p.347.

WATANABE, H. The host population. In: FUXA, J.R.; TANADA, Y. (Ed). Epizootiology of insect diseases. New York: Wiley-Interscience, 1987. 555p. 